\title{
Myelin Gene Regulatory Factor Is Required for Maintenance of Myelin and Mature Oligodendrocyte Identity in the Adult CNS
}

\author{
Matthias Koenning, ${ }^{1}$ Stacey Jackson, ${ }^{1}$ Curtis M. Hay, ${ }^{1}$ Clare Faux, ${ }^{1}$ Trevor J. Kilpatrick, ${ }^{1,2}$ Melanie Willingham, ${ }^{1}$ \\ and Ben Emery ${ }^{1,2}$ \\ ${ }^{1}$ Department of Anatomy and Neuroscience and the Centre for Neuroscience Research and ${ }^{2}$ Florey Neuroscience Institutes, The University of Melbourne, \\ Melbourne, Victoria 3010, Australia
}

\begin{abstract}
Although the transcription factors required for the generation of oligodendrocytes and CNS myelination during development have been relatively well established, it is not known whether continued expression of the same factors is required for the maintenance of myelin in the adult. Here, we use an inducible conditional knock-out strategy to investigate whether continued oligodendrocyte expression of the recently identified transcription factor myelin gene regulatory factor (MRF) is required to maintain the integrity of myelin in the adult CNS. Genetic ablation of MRF in mature oligodendrocytes within the adult CNS resulted in a delayed but severe CNS demyelination, with clinical symptoms beginning at 5 weeks and peaking at 8 weeks after ablation of MRF. This demyelination was accompanied by microglial/macrophage infiltration and axonal damage. Transcripts for myelin genes, such as proteolipid protein, MAG, MBP, and myelin oligodendrocyte glycoprotein, were rapidly downregulated after ablation of MRF, indicating an ongoing requirement for MRF in the expression of these genes. Subsequently, a proportion of the recombined oligodendrocytes undergo apoptosis over a period of weeks. Surviving oligodendrocytes gradually lose the expression of mature markers such as CC1 antigen and their association with myelin, without reexpressing oligodendrocyte progenitor markers or reentering the cell cycle. These results demonstrate that ongoing expression of MRF within the adult CNS is critical to maintain mature oligodendrocyte identity and the integrity of CNS myelin.
\end{abstract}

\section{Introduction}

The process of CNS myelination is tightly regulated both by extrinsic signals provided by neurons and astrocytes and by a network of transcription factors within the oligodendrocyte lineage (for review, see Emery 2010). The use of knock-out mice has identified roles for a number of transcription factors in the generation of oligodendrocytes and their subsequent myelination. Olig2, an early marker of the lineage, is required for the specification of oligodendrocyte progenitors (OPCs) in most regions of the CNS and is thus ultimately required for the generation of mature oligodendrocytes (Lu et al., 2002; Zhou and Anderson, 2002; Ligon et al., 2006). The absence of Olig1 (Xin et al., 2005), Sox10 (Stolt et al., 2002; Takada et al., 2010), Ascl1/Mash1 (Sugimori et al., 2008), YY1 (He et al., 2007), and Nkx2.2 (Qi et al.,

\footnotetext{
Received April 18, 2012; revised June 13, 2012; accepted July 13, 2012.

Author contributions: M.K., T.J.K., and B.E. designed research; M.K., S.J., C.M.H., C.F., M.W., and B.E. performed research; M.K. and B.E. analyzed data; M.K. and B.E. wrote the paper.

This work was supported by the Myelin Repair Foundation and grants from the Australian National Health and Medical Research Council (NHMRC Grant 1009095), the Australian Multiple Sclerosis Society, the Trish Multiple Sclerosis Research Foundation, and National Eye Institute Grant EY10257. B.E. is supported by an NHMRC Career Development Fellowship. We thank Brian Popko for kindly providing the PLP-CreERT mouse line and for helpful discussions. We are indebted to Anna Friedhuber for processing samples for TEM and to Ben Barres and David Lyons for constructive criticism of this manuscript during preparation.

Correspondence should be addressed to Ben Emery, Department of Anatomy and Neuroscience and Florey Neuroscience Institutes, Melbourne Brain Centre, University of Melbourne, Melbourne, VIC 3010, Australia. E-mail: emeryb@unimelb.edu.au.

DOI:10.1523/JNEUROSCI.1069-12.2012

Copyright $\odot 2012$ the authors $\quad 0270-6474 / 12 / 3212528-15 \$ 15.00 / 0$
}

2001) does not prevent the specification of OPCs, but their differentiation is blocked at the late progenitor or premyelinating oligodendrocyte stage, preventing myelination. Recently, we described a previously unknown transcription factor, myelin gene regulatory factor (MRF)/gene model 98, the mouse ortholog to the human gene C11Orf9. Although MRF is not required for the generation of OPCs or their differentiation into premyelinating oligodendrocytes, it is required for the expression of myelin genes and CNS myelination (Emery et al., 2009). Unlike Olig1, Olig2, Sox10, Ascl1, YY1, and Nkx2.2, the expression of MRF is confined to the postmitotic stage of the lineage (Cahoy et al., 2008), and forced expression of MRF in OPCs induces the precocious expression of MBP and MOG (Emery et al., 2009). This suggests that its induction during oligodendrocyte differentiation is a key determinant in initiating myelination.

Whether the transcription factors required for oligodendrocyte differentiation are also required on an ongoing basis in mature cells once myelination is established is unknown. Because of the dysmyelination and early lethality associated with knock-outs for the above factors, this question has not been addressable using conventional knock-out strategies. Recently, inducible conditional knock-out (iCKO) strategies have been used to address this question within the PNS. Genetic ablation of the "master regulator" of PNS myelination Egr2/Krox-20 in the adult results in rapid demyelination, with myelin degeneration and denuded axons found within $3 \mathrm{~d}$ of the ablation of the Krox-20 gene (Decker et al., 2006). Similarly, the inducible genetic ablation of Sox10 in 
myelinating Schwann cells in the adult results in PNS demyelination but with a considerably longer delay (Bremer et al., 2011).

Here, we have used an iCKO strategy to determine whether MRF has a role in the maintenance of myelin by mature oligodendrocytes in the adult. We show that ablation of MRF in myelinating cells causes a delayed but severe CNS demyelination, with clinical signs peaking 8 weeks after ablation of MRF. This demyelination is preceded by a rapid loss of the expression of key myelin genes and coincides with a gradual loss of the mature phenotype and death of many of the recombined oligodendrocytes. These findings demonstrate an ongoing requirement for MRF in the maintenance of both mature oligodendrocyte identity and the myelin sheath.

\section{Materials and Methods}

Mouse lines and genotyping. The MRF exon 8 loxP-flanked line (Emery et al., 2009) was genotyped using primers within intron 7 flanking the first loxP site (AGGAGTGTTGTGGGAAGTGG and CCCAGGCTGAAGATGGAATA), which result in a 281 bp product for the wild-type allele and a 489 bp product for the loxP-flanked allele, respectively. Mice positive for the PLP-CreERT transgene (Doerflinger et al., 2003) were identified with the primers GCGGTCTGGCAGTAAAAACTATC (forward) and GTGAAACAGCATTGCTGTCACTT (reverse), using the internal control primers CTAGGCCACAGAATTGAAAGATCT (forward) and GTAGGTGGAAATTCTAGCATCATCC (reverse). The Rosa26-eYFP reporter line (Srinivas et al., 2001) was genotyped using primers AAGACCGCGAAGAGTTTGTC, AAAGTCGCTCTGAGTTGTTAT and GGAGCGGGAGAAATGGATATG. All mice used were maintained on a mixed C57BL/ $6 \times 129$ background.

Conditional ablation of MRF in myelinating cells. Eight-week-old mice were treated with 4-hydroxytamoxifen (4OHT; Sigma-Aldrich) as described previously (Doerflinger et al., 2003). Briefly, 4OHT was dissolved in $90 \%$ corn oil and $10 \%$ ethanol to $10 \mathrm{mg} / \mathrm{ml}$. Mice were given a daily intraperitoneal injection of $1 \mathrm{mg}(100 \mu \mathrm{l})$ for 5 consecutive days. The first day of injections was designated day 0 .

Rotarod behavioral analysis. Mice were trained for three trials on the rotarod at a constant speed (4 rpm), 120 s per trial. Subsequent weekly test runs consisted of three trials on an accelerating rotarod for up to $300 \mathrm{~s}$ (starting at $4 \mathrm{rpm}$ accelerating to a final speed of $40 \mathrm{rpm}$ ), with mice returned to their home cages for at least $15 \mathrm{~min}$ between trials. Clinical grades were assessed using an experimental autoimmune encephalomyelitis (EAE) grading system modified to reflect the phenotype of the inducible MRF knock-outs as follows: grade 0 , no overt symptoms; grade 1 , loss of tail tone; grade 2, loss of tail tone with mild hindlimb involvement (wide gait) or ataxia; grade 3, substantial hindlimb weakness (mouse cannot hang from hindlimbs) and ataxia; grade 4, severe hindlimb weakness (forelimbs mostly used for locomotion) and ataxia; and grade 5, complete hindlimb paralysis (clinical endpoint; mice were killed at this grade or if they suffered from $>15 \%$ weight loss).

Tissue processing and immunostaining of cryosections. Mice were anesthetized with sodium pentobarbital (100 mg/kg, i.p.) and transcardially perfused with $10 \mathrm{ml}$ of PBS and $20 \mathrm{ml}$ of $4 \%$ PFA. Optic nerves, brains, and spinal cords were removed, postfixed in $4 \%$ PFA for $2 \mathrm{~h}$, sunk in $30 \%$ sucrose in PBS overnight at $4^{\circ} \mathrm{C}$, and embedded in OCT, and $10 \mu \mathrm{m}$ cryosections were cut. Sections were blocked in 10\% FCS with $0.3 \%$ Triton X-100 and stained overnight in the following antibodies: rat anti-MBP (MAB386; Millipore), CC1 monoclonal (Millipore), rabbit anti-NG2 (AB5320; Millipore), mouse anti-CD68 (MCA1957B; AbD Serotec), rat anti-CD3 (555273; BD Pharmingen), mouse anti-GFAP (MAB360; Millipore), rabbit anti-Sox10 (AB5727; Millipore), rabbit anti- $\beta$-APP (51-2700; Life Technologies), and rabbit anti-active caspase-3 (BD Pharmingen). Sections were then incubated with the appropriate fluorescent conjugated antibodies (Alexa Fluor; Life Technologies). FluoroMyelin staining (Life Technologies) was conducted for $2 \mathrm{~h}$ at 1:300 in PBS before four 30-min washes in PBS.

Cumulative detection of dividing cells. For detection of proliferating cells in vivo, mice were given $5^{\prime}$-ethynyl-2'-deoxyuridine (EdU) (Life
Table 1. qPCR primers

\begin{tabular}{|c|c|c|}
\hline & Forward & Reverse \\
\hline 185 ribosomal subunit & CGGCTACCACATCCAAGGAA & GCTGGAATTACCGCGGCT \\
\hline $\operatorname{MRF}(\text { total })^{a}$ & GCATGGGCACCGCCCCTAAG & GGGGCGAGTCTGGCAGTGTG \\
\hline MRF (non-recombined) ${ }^{b}$ & AAGGAGCTGCCTATGCTCACCT & GCCTCTAGCTTCACACCATGCA \\
\hline MRF $\left(\right.$ recombined) ${ }^{c}$ & ATCCATCAAATGGCAGCCGCA & CAGGGCCTCTAGAGCTCCTT \\
\hline MAG & AACCAGTATGGCCAGAGAGC & GTTCCGGGTTGGATTTTACC \\
\hline PLP1 & GCCCCTACCAGACATCTAGC & AGTCAGCCGCAAAACAGACT \\
\hline MBP & CCCGTGGAGCCGTGATC & TCTTCAAACGAAAAGGGA \\
\hline MOG & ATGAAGGAGGCTACACCTGC & CAAGTGCGATGAGAGTCAGC \\
\hline Sox 10 & TGGACCGCACACCTTGGGACA & ACGCCCACCTCCTCCGACCT \\
\hline CNP & GTTCTGAGACCCTCCGAAAA & CCTTGGGTTCATCTCCAGAA \\
\hline $\operatorname{PDGFR} \alpha$ & GGAAGGACTGGAAGCTTGGGGC & GAGATGAGGCCCGGCCCTGTGA \\
\hline CD68 & GGACTACATGGCGGTGGA & GATGAATTCTGCGCCATGAA \\
\hline$\beta$-3-tubulin & TCTCGGCCTCGGTGAACTC & AAGGCCTTCCTGCACTGGTA \\
\hline
\end{tabular}

${ }^{a}$ Recognized transcripts arising from both non-recombined and recombined alleles.

${ }^{b}$ Specific to non-recombined allele.

'Specific to post-recombination/nonfunctional allele.

Technologies) dissolved in the drinking water at $0.2 \mathrm{mg} / \mathrm{ml}$. The water was exchanged every $72 \mathrm{~h}$, and mice were exposed to EdU from 1 week after the first 4OHT injection until the time the animals were killed (2-8 weeks after 4OHT). For detection of EdU incorporation, sections were first processed for eYFP or CC1 immunohistochemistry as above and then developed using the Alexa Fluor-594 Click-iT EdU Cell Proliferation Assay kit (Life Technologies) as per the instructions of the manufacturer.

In situ hybridization. In situ hybridization was performed as described previously (Faux et al., 2010) using DIG-labeled antisense riboprobes for the 3' UTR region of MRF (Emery et al., 2009) or probes against PDGFR $\alpha$ or proteolipid protein (PLP) (constructs kindly provided by Prof. William Richardson, University College London, London, UK).

Semiquantitative RT-PCR. Spinal cords were dissected from control $\left(\mathrm{MRF}^{\mathrm{FL} / \mathrm{FL}}\right)$ and $\mathrm{iCKO}\left(\mathrm{MRF}^{\mathrm{FL} / \mathrm{FL}}\right.$; PLP-CreERT) mice at indicated times after 4OHT. Total RNA was isolated using microRNeasy kits (Qiagen) as per the instructions of the manufacturer. cDNA was generated using superscript III kit (Life Technologies). Semiquantitative PCR was then performed using primers either flanking the cDNA encoded for by the loxP-flanked exon 8 (GCCTCAGTGGCTCCTATTTG and GATCGGAAGGGTGCATAAGA) or within the cDNA encoded for by exons 7 and 8 (CCCCCAGCATGCCGATGTACAC and TGTACACGGTCACCTGGAAG). $\beta$-Actin cDNA was amplified as a loading control using primers TGTTACCAACTGGGACGACA and AAGGAAGGCTGG AAAAGAGC.

Quantitative PCR. Total RNA was isolated from hemi-brains of mice using the Qiagen RNeasy Lipid mini-kit as per the instructions of the manufacturer. RNA, at $1 \mu \mathrm{g}$, was used for a reverse transcriptase reaction with the Taqman Reverse Transcription reagents (Applied Biosystems), according to the instructions of the manufacturer, and used at a dilution of 1:20 for the quantitative real-time PCR (qPCR) reactions. qPCR was performed on an ABI7700 sequence detection system (Applied Biosystems). Relative expression from amplified RNA samples was determined using the $2^{-\Delta \Delta}$ CT method (Pfaffl, 2001). Values were normalized to the expression of the $18 \mathrm{~S}$ ribosomal subunit within samples and then normalized to mean values for the control group. Primers were designed using Primer3 (National Center for Biotechnology Information) and the qPrimerDepot (primerdepot.nci.nih.gov/). Primer sequences are listed in Table 1.

Western blot analysis of protein expression. Hemi-brain samples or spinal cords (from the same animals used in the qPCR study) were homogenized in RIPA buffer with PMSF and complete protease inhibitors (Roche) via douncing and subsequent sonication. Lysates were spun twice at $21,500 \times g$ at $4^{\circ} \mathrm{C}$ for $20 \mathrm{~min}$ to remove insoluble material. Fifty micrograms of protein were run on a $10 \%$ Bis-Tris gradient gel (Life Technologies) and transferred to PVDF membrane (Millipore). Blots were probed with an in-house monoclonal antibody against mouse MRF before being stripped and reprobed with anti- $\beta$-actin to confirm even loading. Control and MRF-transfected HEK293T cell lysates were used as 

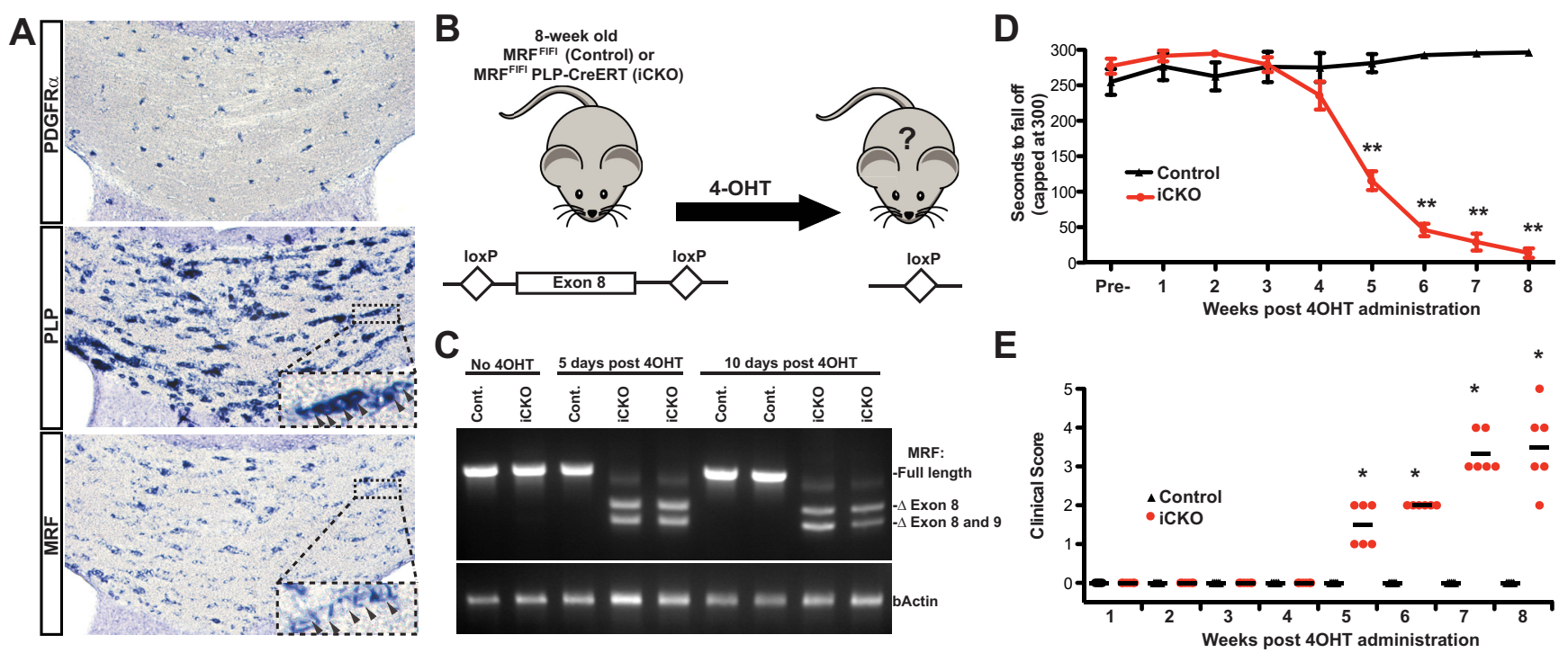

Figure 1. Inducible loss of MRF causes a progressive behavioral deficit. A, In situ hybridization for PDGFR $\alpha$, PLP, and MRF in the corpus callosum of an 8-week-old mouse. Probes for both PLP and MRF label chains of oligodendrocytes (insets). B, Strategy used to inactivate MRF in myelinating cells in 8-week-old mice. C, RT-PCR analysis of recombination using primers flanking the RNA encoded by the loxP-flanked exon. After $40 \mathrm{HT}$ administration, the full-length transcript is essentially replaced by the truncated transcript lacking exon 8 or exons 8 and 9 in iCKO mice. $D$, Rotarod analysis of motor function in control or iCKO mice from 0 to 8 weeks after $40 \mathrm{HT}$. Values are mean \pm SEMs, $n=6$ animals per genotype. ${ }^{*} p<0.05,{ }^{* *} p<0.01$. $E$, Clinical disease scores for the same cohort shown in $\boldsymbol{D}$.

a negative and positive control for MRF expression, respectively. For quantitative MBP blots, gels were transferred on to PVDF-Fl membranes (Millipore). The membranes were blocked in Odyssey blocking buffer (Li-Cor) and probed with antibodies against either MBP (MAB386; Millipore) or PLP (MAB388; Millipore) and $\beta$-actin (A-2228; SigmaAldrich). Blots were then probed with the appropriate 680LT and 800CW conjugated secondary antibodies (926-32211 and 926-68020; Li-Cor) and imaged on an Odyssey Clx infrared imaging system (LiCor). Band intensities were quantified using the Li-Cor software, with MBP levels normalized within samples to $\beta$-actin, and then compared with controls.

Electron microscopy. Mice were anesthetized with sodium pentobarbital ( $100 \mathrm{mg} / \mathrm{kg}$, i.p.) and transcardially perfused with $10 \mathrm{ml}$ of PBS and 20 $\mathrm{ml}$ of $4 \%$ PFA, $2.5 \%$ glutaraldehyde in $0.1 \mathrm{M}$ cacodylate buffer, $\mathrm{pH}$ 7.2. Spinal cords and optic nerves were postfixed for $48 \mathrm{~h}$ in this fixative buffer before being processed for resin embedding. Semithin sections $(0.5 \mu \mathrm{m})$ were cut and stained with toluidine blue to evaluate quality and orientation of tissue. Representative samples were then chosen, ultrathin sections $(90 \mathrm{~nm})$ were cut, and images were captured using a Siemens Stereoskop Transmission Electron at $3000 \times$ or $10,000 \times$.

Quantification and statistics. For cell counts on cryosections, images were taken using either the $20 \times$ or $40 \times$ objectives of three to six sections per animal, with these sections being $100 \mu \mathrm{m}$ or more apart. Exposure times and any post-capture adjustments in brightness or contrast were kept constant for all images to be directly compared. Cell counts and areas were determined on blinded images using NIH Image J software, and mean densities were calculated for each animal from these analyses. Because of the low incidence of active caspase-3-positive $\left(\right.$ caspase- $3^{+}$) cells, these counts were performed on 9-12 whole spinal cord sections per animal. For analysis of proportions of axons myelinated, 10,000 $\times$ EM images (three per animal) were imported into NIH Image J, and all axons within the images were quantified as myelinated or nonmyelinated. For $g$-ratio analysis, EM images were imported into NIH Image J, and the external circumference of the myelin and axons was measured. These measurements were converted to diameters and used for $g$-ratio calculations (axonal diameter/external myelin diameter). For each animal ( $n=3$ /genotype), 37-50 myelinated optic nerve axons and 50-100 myelinated spinal cord axons were measured, measuring all myelinated axons falling within the images assessed. For all analyses (cell counts, percentage axons myelinated, $g$-ratios, and rotarod tests), individual means were calculated for each animal, and the means and SEMs were then calculated for each experimental group based on these individual means. Statistical significance of clinical scores was assessed using a Wilcoxon's signed-rank test, and significance of other data were calculated using two-way ANOVAs with Bonferroni's post hoc tests using Prism software. All data are depicted as mean \pm SEM.

All experiments were approved by and conducted in accordance with the Florey Neuroscience Institutes Animal Ethics committee.

\section{Results}

\section{Continuous oligodendrocyte expression of MRF is required to maintain myelin integrity}

Although the expression of MRF is maintained within oligodendrocytes in the adult CNS (Allen Brain Atlas and Fig. 1A), the functional significance of this ongoing expression is unknown. To generate mice in which the MRF gene could be inactivated in mature myelinating cells in a temporally controlled manner, we crossed the MRF exon 8 loxP-flanked $\left(\mathrm{MRF}^{\mathrm{FL}}\right)$ mouse line (Emery et al., 2009) with a PLP-CreERT transgenic line expressing a tamoxifen-inducible Cre in myelinating cells (Doerflinger et al., 2003). We treated control $\left(\mathrm{MRF}^{\mathrm{FL} / \mathrm{FL}}\right)$ and $\mathrm{iCKO}\left(\mathrm{MRF}^{\mathrm{FL} / \mathrm{FL}}\right.$; PLP-CreERT) mice with $4 \mathrm{OHT}$ at 8 weeks of age (Fig. $1 \mathrm{~B}$ ), by which time the majority of developmental myelination is established (Agrawal et al., 2009). Semiquantitative RT-PCR analysis of RNA isolated from spinal cords confirmed that, in the absence of $4 \mathrm{OHT}$ administration, both control and iCKO mice expressed the full-length MRF transcript. Within $5 \mathrm{~d}$ of the first $4 \mathrm{OHT}$ injection, the full-length RT-PCR product in the $\mathrm{iCKO}$ mice was primarily replaced by two shorter amplified products lacking the RNA coded for by the loxP-flanked exon 8 or exons 8 and 9 (confirmed by sequencing of the RT-PCR products; data not shown). This confirmed both rapid and substantial Cremediated recombination and inactivation of the loxP-flanked MRF allele after 4OHT administration (Fig. 1C).

Despite the rapid Cre-mediated ablation of the floxed MRF allele, $\mathrm{iCKO}$ mice remained overtly normal for $\sim 5$ weeks after $4 \mathrm{OHT}$ injection. However, from 5 weeks after $4 \mathrm{OHT}$, the iCKO mice displayed progressive motor deficits relative to controls as assessed by the rotarod test of motor function (Fig. 1D). These 


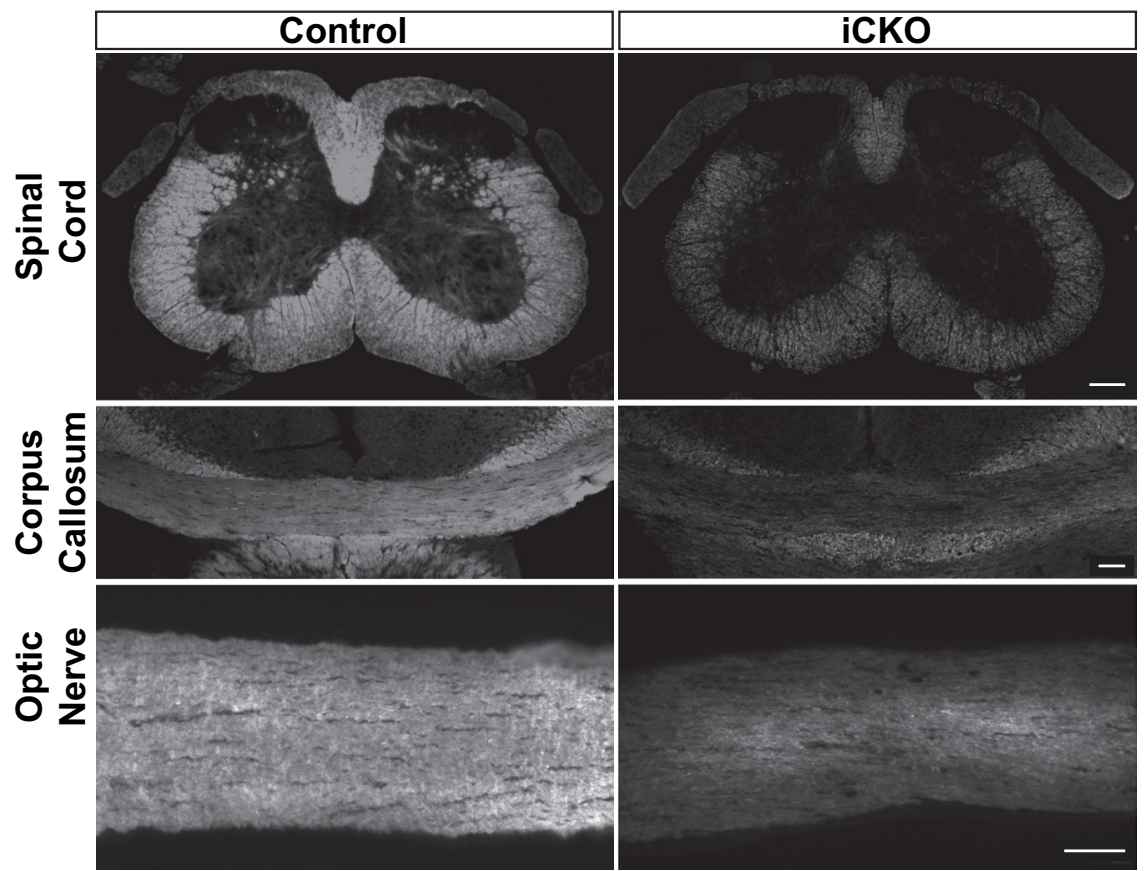

Figure 2. Representative images of FluoroMyelin staining of key white matter regions (spinal cord, corpus callosum, and optic nerve) of control and iCKO mice at 8 weeks after $40 \mathrm{HT}$. Widespread demyelination is evident throughout all these regions in the iCKO mice. Scale bars, $100 \mu \mathrm{m}$.

rotarod deficits were confirmed by clinical symptoms consistent with CNS demyelination, including ataxia, shivering, and tail and hindlimb weakness, quantified in Figure $1 E$ using a modified EAE clinical scoring system. This overt phenotype typically peaked at 8 weeks after $4 \mathrm{OHT}$, at which time point all iCKO mice would show varying degrees of ataxia and hindlimb weakness, with some also showing significant forelimb weakness. Typically, $\sim 30 \%$ of iCKO mice needed to be killed as a result of substantial weight loss and/or loss of mobility at 8-9 weeks after 4 OHT.

FluroMyelin staining of cryosections from animals 8 weeks after 4OHT injections revealed widespread and severe demyelination in all the CNS regions analyzed in the iCKO mice, including the optic nerve, corpus callosum, and spinal cord (Fig. 2 ). This demyelination was confirmed by EM analysis of sections from the optic nerves and spinal cord lateral white matter, with iCKO mice displaying myelin vacuolization, denuded axons, and myelin debris (Fig. $3 A, B$ ). The degeneration and/or clearance of myelin appeared to have occurred more rapidly in the optic nerves than the spinal cords; whereas the optic nerves typically contained comparatively little myelin debris and many examples of thin myelin, indicative of remyelination in progress (Fig. $3 C$ ), the spinal cords typically contained more extensive myelin debris and actively degenerating myelin sheaths (Fig. 3D). Quantification of the proportion of axons myelinated in each area revealed that the percentage of axons myelinated in the iCKO mice was reduced from $95.0 \pm 1.3$ to $31.0 \pm 7.9 \%$ in the optic nerve $(p<$ $0.05)$ and from $79.6 \pm 6.2$ to $34.1 \pm 5.2 \%$ in the spinal cord $(p<$ 0.01 ). Given the additional observations that many of the remaining myelin sheaths were either thin or actively degrading, these results are consistent with the majority of CNS myelin being lost after ablation of MRF.

\section{Demyelination caused by MRF ablation is partially recoverable}

To assess whether the demyelination seen after MRF ablation was recoverable, mice ( $n=3$ /genotype) were maintained over an 8 month period after $4 \mathrm{OHT}$ injection. In all cases, the iCKO mice reached a peak clinical score of 4 (displaying severe tail and hindlimb weakness, shivering, and ataxia) at 8 weeks after $4 \mathrm{OHT}$, which subsided to relatively stable clinical scores of 1 or 2 within 4 months after $4 \mathrm{OHT}$. Tissue taken at 8 months after $4 \mathrm{OHT}$ showed evidence of substantial remyelination within the optic nerves and spinal cord, including an increase in the proportion of myelinated axons relative to mice taken at clinical peak (Fig. $3 E, F$ ), although this difference was statistically nonsignificant as a result of the high degree of variability in the recovery cohort. $g$-ratio analysis of the myelinated axons at 8 months after $4 \mathrm{OHT}$ showed a significant increase in the average $g$-ratio in iCKO mice compared with the control mice in each area $(0.71 \pm 0.01$ vs $0.78 \pm 0.01$ for control and $\mathrm{iCKO}$ mice in the optic nerve, $p<0.05$ and $0.64 \pm$ 0.01 vs $0.71 \pm 0.01$ for control and $\mathrm{iCKO}$ mice in the spinal cord, $p<0.05$ ), consistent with the majority of myelin present in the optic nerves and spinal cords of the iCKO mice being remyelination derived (plots of individual $g$-ratios as a function of axonal diameter shown for each area in Fig. $3 G, H)$.

\section{MRF ablation results in a loss of myelin gene and protein expression}

During oligodendrocyte differentiation, the induction of MRF is required for the expression of a group of genes known to underpin the myelination process or to be protein components of myelin structures, such as MBP, PLP, MAG, and MOG (Emery et al., 2009). To assess whether ablation of MRF caused a dysregulation of these genes, we performed qPCR on brain cDNA samples from control and iCKO mice in the absence of $4 \mathrm{OHT}$ ( 0 weeks) or 1, 2, 4,6 , or 8 weeks after $4 \mathrm{OHT}$. Using primers that do not distinguish between the non-recombined and recombined/nonfunctional MRF alleles, the expression of MRF itself was modestly decreased in the iCKOs after $4 \mathrm{OHT}$, with this only being statistically significant at 2 and 4 weeks after 4OHT. In contrast, qPCR primers specific to the loxP-flanked exon of MRF showed that, at 1 week after $4 \mathrm{OHT}$, the brains of iCKO mice displayed an $86 \pm 0.53 \%$ reduction in levels of the non-recombined transcript relative to controls (Fig. 4A). This was accompanied by a corresponding peak in the expression of the recombined allele. Although expression of the recombined allele progressively declined from 1 week after 4OHT, expression of the non-recombined allele partially recovered at 6-8 weeks after $4 \mathrm{OHT}$ (Fig. $4 A$ ). To assess whether the MRF protein showed the same kinetics as the RNA, we blotted spinal cord lysates from the same mice with a monoclonal antibody against MRF. The protein showed an essentially identical profile to the non-recombined allele, being undetectable in the iCKO mice at 1-4 weeks after $4 \mathrm{OHT}$ and being reexpressed at 6 and 8 weeks after $4 \mathrm{OHT}$ (Fig. $4 \mathrm{~B}$ ).

The expression of the key myelin genes PLP and MAG closely mirrored that of the functional MRF mRNA during this time course, showing an equivalent decrease at 1 week after $4 \mathrm{OHT}$ and a subsequent recovery at 6-8 weeks after $4 \mathrm{OHT}$ (Fig. $4 A$ ). In contrast, the expression of MBP and MOG showed a more mod- 
A
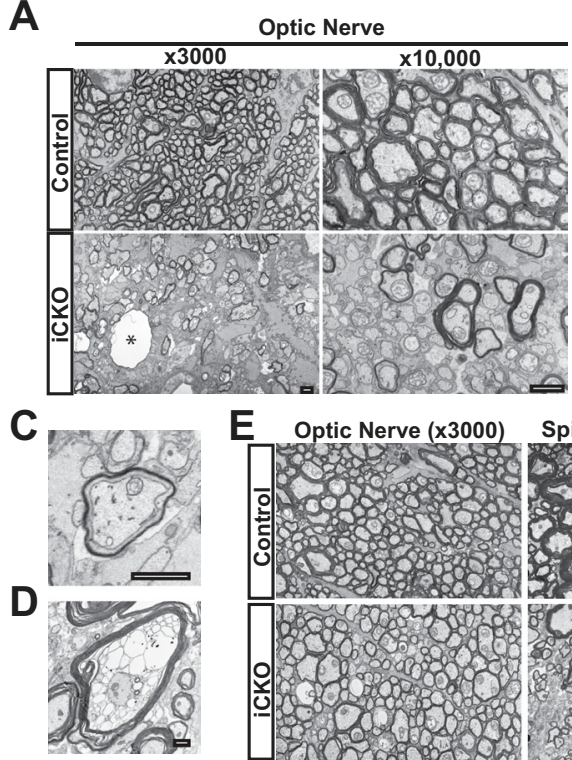

B

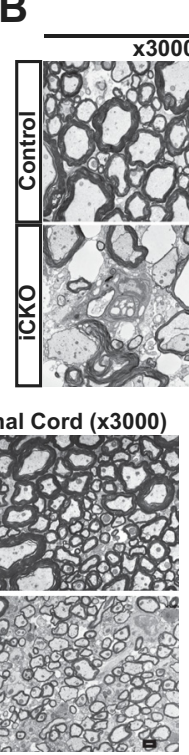

Spinal Cord

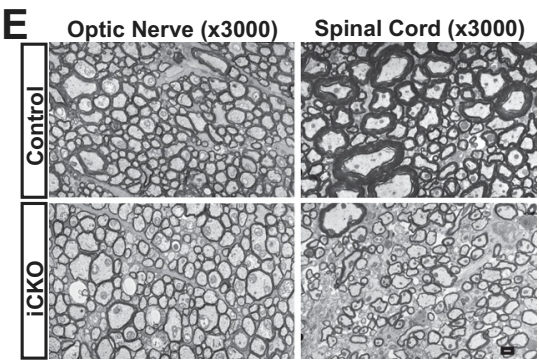

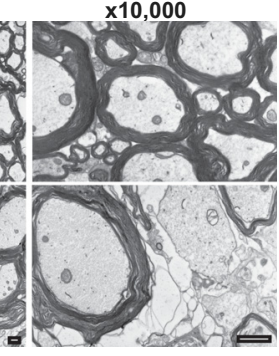

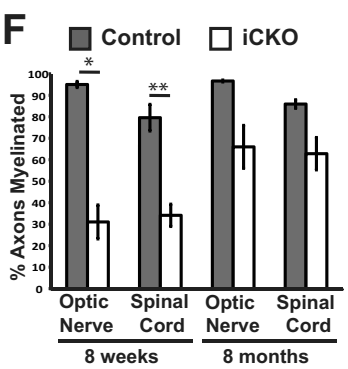

G

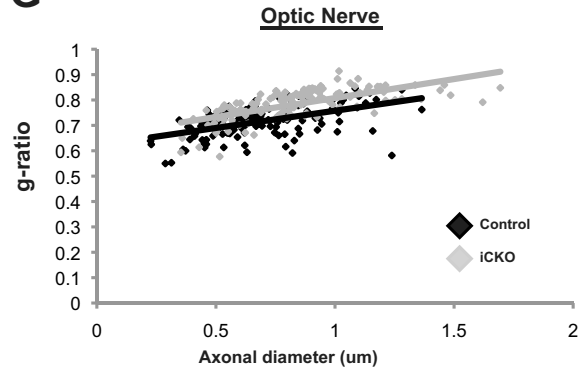

$\mathbf{H}$

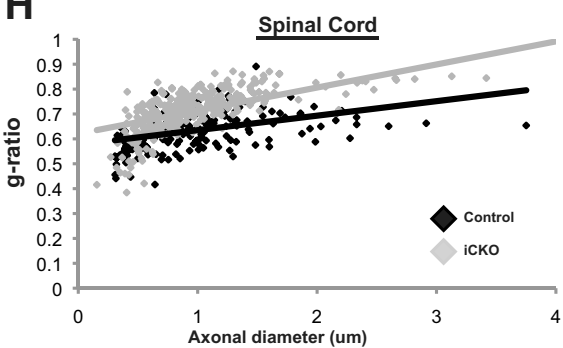

Figure 3. Ablation of MRF causes severe demyelination. $A$, Electron microscopy analysis of the optic nerve at 8 weeks after $40 \mathrm{HT}$ reveals substantial demyelination and other signs of myelin pathology, such as vacuolization $\left(^{*}\right)$ in the iCKO mice. $B$, At 8 weeks after $40 \mathrm{HT}$, the lateral white matter of the spinal cord contains more signs of active demyelination, including substantial vacuolization, delamination, and myelin debris. $\boldsymbol{C}, \boldsymbol{D}$, Higher-magnification images of a thinly myelinated (presumably remyelinated) axon in the optic nerve $(\boldsymbol{C})$ and degrading myelin in the spinal cord (D).E, At 8 months after 40HT, both the optic nerve and spinal cord of the iCKO mice show substantial remyelination as evidenced by numerous thinly myelinated axons. $F$, Quantification of the proportion of axons myelinated in the optic nerve and lateral white matter of the spinal cord of iCKO mice and controls at 8 weeks and 8 months after $40 \mathrm{HT}$ administration. Data are means \pm SEM. ${ }^{*} p<0.05,{ }^{* *} p<0.01 . n=3$ animals per condition. Scale bars, $1 \mu \mathrm{m} . \boldsymbol{G}, \boldsymbol{H}, g$-ratios of individual axons as a function of axonal diameter in the spinal cord $(\boldsymbol{G})$ and optic nerve $(\boldsymbol{H})$ in controls and iCKOs at 8 months after 40HT.

est decline and took 4 weeks after ablation of MRF to reach their lowest levels of $\sim 40 \%$ of control values. Despite the severe loss of myelin genes, such as MBP, PLP, MAG, and MOG, the expression of the oligodendrocyte lineage marker Sox10 was not reduced in the iCKO mice (in fact, it was slightly increased), nor was the expression of $\mathrm{CNP}$, which we have found previously to not be dependent on MRF for its expression during development (Emery et al., 2009). The expression of PDGFR $\alpha$ increased modestly in iCKO mice relative to controls at 6 and 8 weeks after 4OHT, suggesting an OPC proliferative or reactive response to the demyelination. The expression of the neuron-specific gene $\beta$-3tubulin remained equivalent between $\mathrm{MRF}^{\mathrm{FL} / \mathrm{FL}}$; PLP-CreERT and control animals throughout the 8 weeks after $4 \mathrm{OHT}$. To assess whether the downregulation of MBP mRNA observed after $4 \mathrm{OHT}$ injection resulted in a detectable loss of the protein, we performed quantifiable infrared Western blots against MBP from brain protein lysates from the same cohort of animals as used for the qPCR study (Fig. 5). In contrast to the rapid loss of myelin gene expression after ablation of MRF, the loss of MBP protein was delayed, with a significant decrease in MBP expression only detectable in the iCKO mice at 8 weeks after $4 \mathrm{OHT}$.

\footnotetext{
Ablation of MRF in myelinating oligodendrocytes causes a loss of both mature oligodendrocyte markers and viability of the recombined cells

Given the rapid and substantial loss of key myelin gene transcripts (as assessed by qPCR) and the eventual loss of myelin (as assessed by EM analysis) after the ablation of MRF, we next sought to investigate the effects of MRF ablation on the recombined cells themselves. To assess the status of cells from the oligodendrocyte lineage at the peak of clinical severity, we stained spinal cord and optic nerve sections from $\mathrm{iCKO}$ and control mice at 8 weeks after $4 \mathrm{OHT}$ for Sox10, NG2, and CC1. Somewhat unexpectedly given the severe demyelination seen at this time
}

point, the densities of $\mathrm{CC}^{+}$cells were strikingly similar between control and iCKO mice in the optic nerves and dorsal white matter of the spinal cord (Fig. 6) but were decreased significantly in the spinal cord lateral white matter columns of the iCKO mice $(p<0.01)$. Despite the preserved numbers of $\mathrm{CC}^{+}$oligodendrocytes, their size and the expression levels of $\mathrm{CC} 1$ were less regular in the iCKO mice than in control mice, and the linear arrays of oligodendrocytes were clearly disrupted. All three regions showed a modest but statistically significant increase in the density of NG2 ${ }^{+}$cells (Fig. $6 D$ ).

The presence of significant numbers of $\mathrm{CC}^{+}$oligodendrocytes in the iCKO mice at a time of substantial demyelination could be attributable to the original recombined oligodendrocytes persisting despite being unable to maintain their myelin sheaths, to new oligodendrocytes derived from OPCs generated in response to the demyelination, or to a combination of the above. We therefore took a genetic labeling approach to allow identification of the original recombined oligodendrocytes, crossing the $\mathrm{MRF}^{\mathrm{FL} / \mathrm{FL}} / \mathrm{PLP}-\mathrm{CreERT}$ mice onto the Rosa26eYFP reporter line (Srinivas et al., 2001). $\mathrm{MRF}^{\mathrm{FL} / \mathrm{FL}}$ (iCKO) or $\mathrm{MRF}^{\mathrm{WT} / \mathrm{FL}}$ (control) mice positive for both the PLP-CreERT and Rosa26-eYFP alleles were injected with 4OHT at 8 weeks of age. Sections were taken from the optic nerve and spinal cord in noninjected animals ( 0 week) and mice at 2, 4, 6, and 8 weeks after $4 \mathrm{OHT}$ to assess the fate of the recombined cells.

Confirming the previous results at 8 weeks after $4 \mathrm{OHT}$, no significant difference was found between the $\mathrm{MRF}^{\mathrm{FL} / \mathrm{FL}}$ mice and MRF ${ }^{\mathrm{WT} / \mathrm{FL}}$ controls in the density of $\mathrm{CC}^{+}{ }^{+}$oligodendrocytes in the optic nerve or dorsal spinal cord at any point during the 8 weeks after $4 \mathrm{OHT}$ (Fig. $7 A, B, F$ ). Before $4 \mathrm{OHT}$ injection, both genotypes had a low percentage of $\mathrm{CC} 1$ immunopositive oligodendrocytes expressing eYFP ( $<3 \%$ for both genotypes), indicating that the PLP-CreERT transgene can cause a low basal level of "leaky" recombination in the absence of $4 \mathrm{OHT}$ administration. 
A

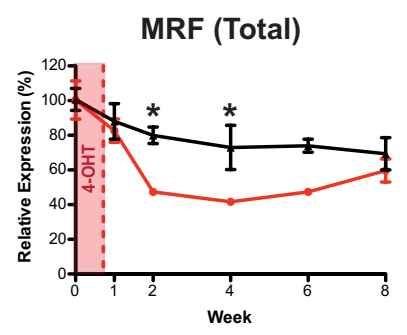

PLP
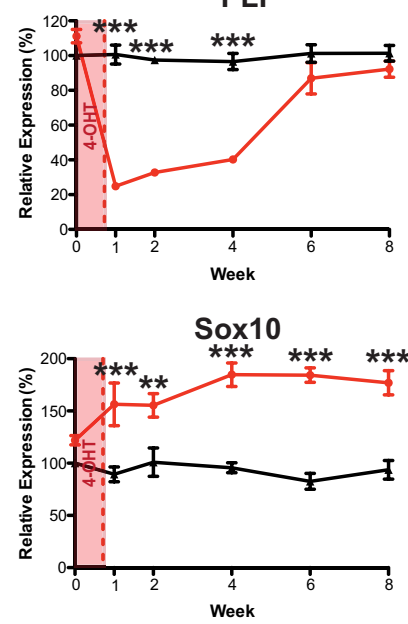

MRF (Non-recombined)

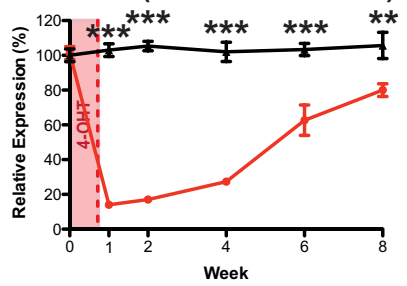

MAG

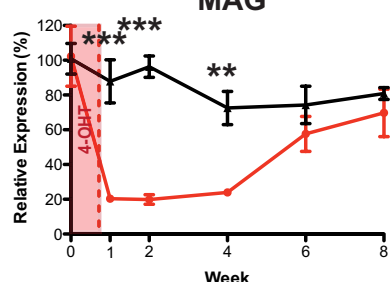

PDGFR $\alpha$

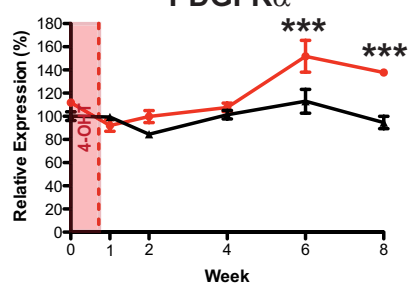

$-\mathrm{iCKO} \rightarrow$ Control

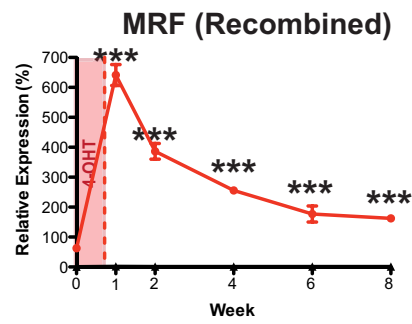

MBP

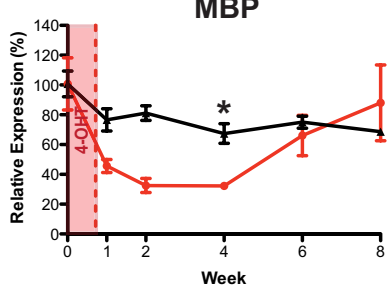

CD68

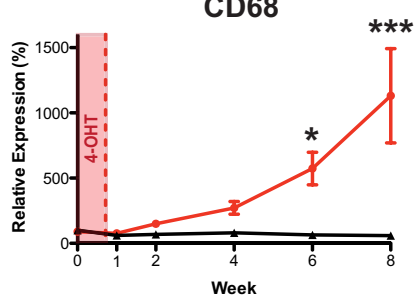

CNP

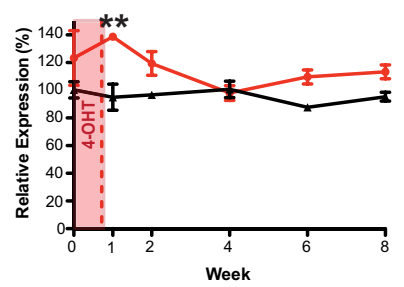

MOG

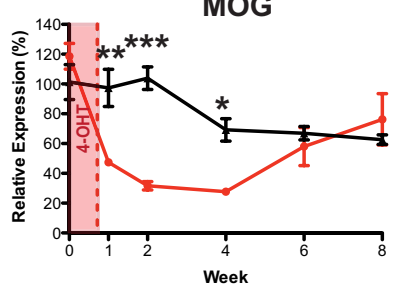

$\beta$-3-Tubulin

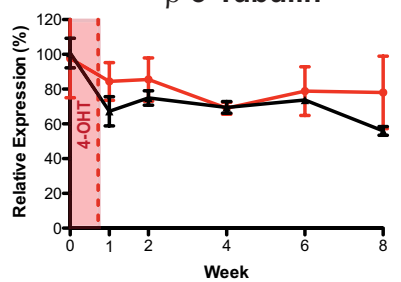

B
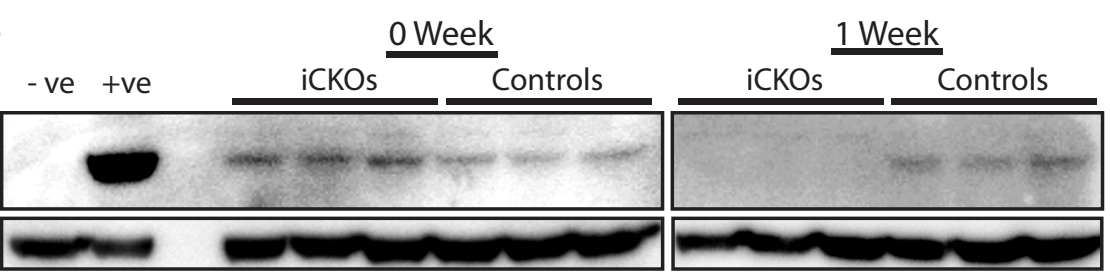

iCKOs

2 Weeks
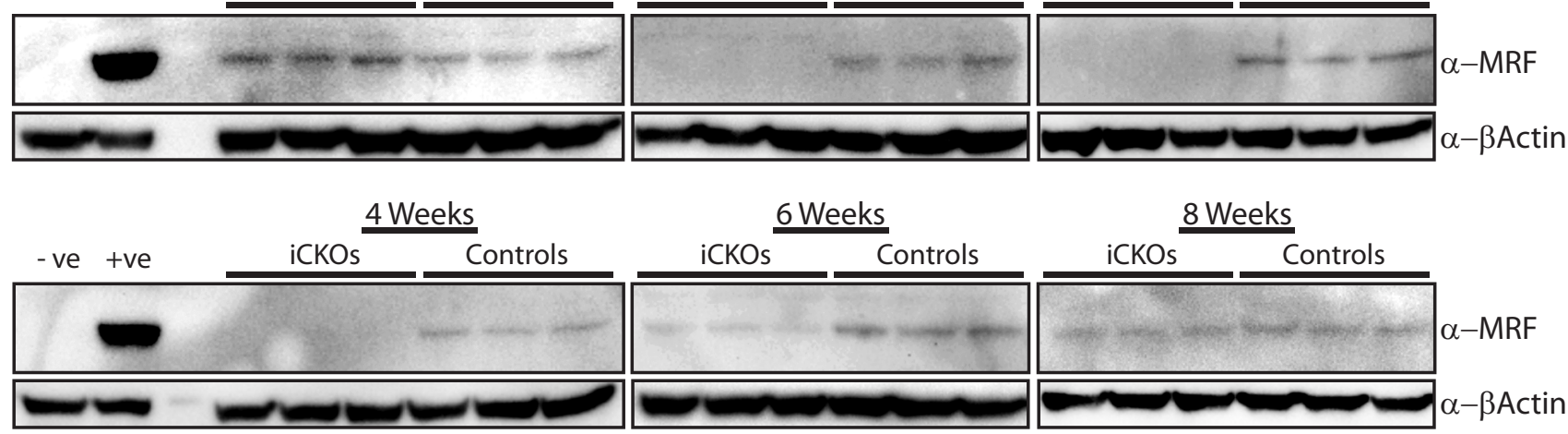

Figure 4. A, qPCR analysis of expression of key genes, including MRF, myelin genes (CNP, MAG, PLP, MBP, and MOG), oligodendrocyte lineage markers (Sox10 and PDGFR $\alpha$ ), and markers of microglia/macrophages (CD68) and neurons ( $\beta$-3-tubulin) after ablation of MRF. Graphs show mean \pm SEM expression for each group relative to the mean of the uninjected control (PLP-CreERT ${ }^{+}$) group. $n=3$ animals per condition. ${ }^{*} p<0.05,{ }^{* *} p<0.01,{ }^{* *} p<0.001$. All comparisons between genotypes within time points. $\boldsymbol{B}$, Western blot analysis of MRF protein expression in the spinal cords of the same animals as in $\boldsymbol{A}$. Negative and positive controls for MRF expression are lysates from nontransfected and MRF-transfected HEK293T cells, respectively.

At 2 weeks after $4 \mathrm{OHT}$, both genotypes displayed a similar recombination efficiency, with $\sim 50 \%$ of $\mathrm{CC}^{+}$oligodendrocytes expressing the eYFP reporter (a lower efficiency of recombination at the Rosa26eYFP allele compared with the $\mathrm{MRF}^{\mathrm{Fl}}$ allele). Almost all these $\mathrm{eYFP}^{+}$cells were positive for CC1 $(>98 \%$ in both genotypes), confirming specificity of recombination to mature oligodendrocytes. In MRF WT/FL controls, the proportion of $\mathrm{CC}^{+}$oligodendrocytes expressing $\mathrm{eYFP}^{+}$remained stable between 2 and 8 weeks after 4OHT. In contrast, the iCKO mice displayed a substantial decrease in the proportion of $\mathrm{CC}^{+}{ }^{+}$oligodendrocytes that were $\mathrm{eYFP}^{+}$within both the optic nerve and spinal cord at 6 and 8 weeks after $4 \mathrm{OHT}$ (Fig. $7 C-G$ ), suggesting that many of the recombined iCKO oligodendrocytes were replaced with new oligodendrocytes derived from non-recombined
OPCs. This interpretation was also supported by a progressive decrease in the density of eYFP ${ }^{+}$cells in the optic nerves and spinal cords of the iCKO mice; by 6 and 8 weeks after $4 \mathrm{OHT}$, the density of $\mathrm{eYFP}^{+}$cells had declined by approximately one-half to two-thirds (Fig. $7 D-H$ ).

Analysis of the proportion of eYFP ${ }^{+}$cells in each genotype expressing CC1 showed that, over time, many of the surviving $\mathrm{eYFP}^{+}$cells within the optic nerve and spinal cords of the iCKO mice downregulated or lost the mature marker $\mathrm{CC} 1$ antigen. In contrast, the vast majority $(>97 \%)$ of $\mathrm{eYFP}^{+}$cells in the MR$\mathrm{F}^{\mathrm{WT} / \mathrm{FL}}$ controls remained $\mathrm{CCl}^{+}$at all time points (Fig. $7 A, E, I$ ). Despite this loss of the marker CC1, there was no evidence of reexpression of markers of the OPC stage of the lineage. In an analysis of several hundred $\mathrm{eYFP}^{+}$cells costained with NG2 at 


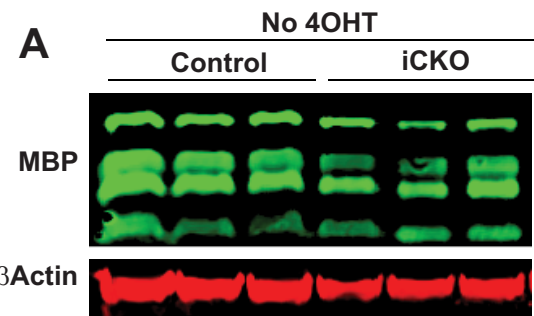

6 weeks post $4 \mathrm{OHT}$

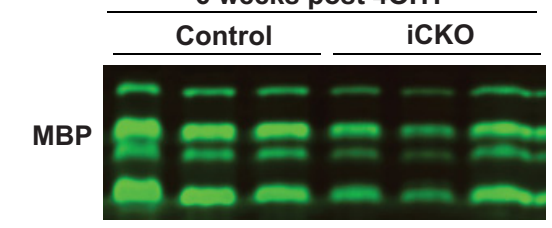

$\beta$ Actin

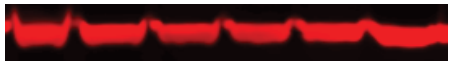

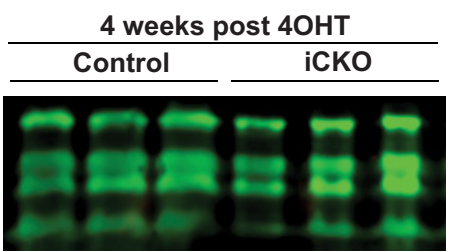

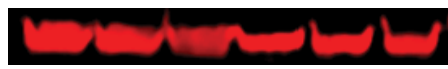

8 weeks $4 \mathrm{OHT}$

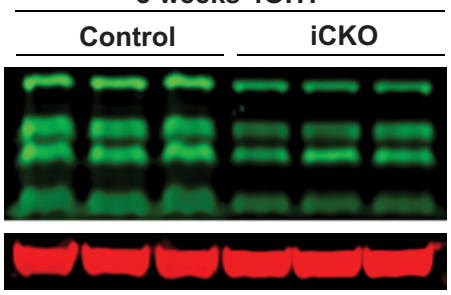

B

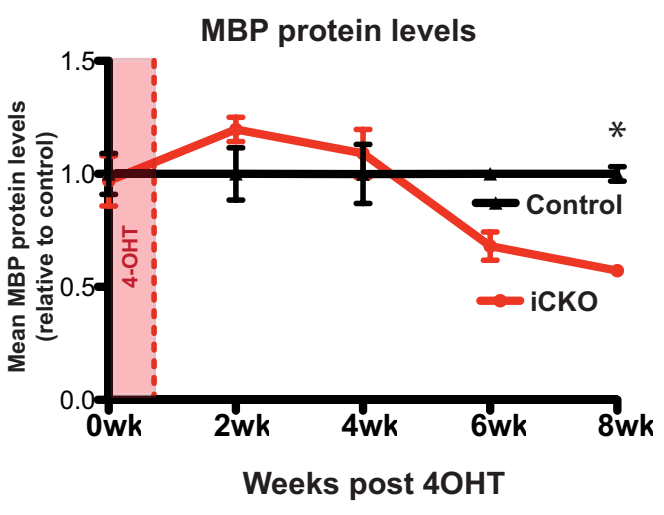

Figure 5. Quantitative infrared Western blot analysis of MBP protein expression after ablation of MRF. $A$, Western blots of MBP and $\beta$-actin from iCKOs and controls at 0,4 , and 8 weeks after $40 \mathrm{HT}$. $B$, Quantification of MBP levels. Graphs show mean \pm SEM expression for each group relative to the mean of the control group at each time point. $n=3-4$ animals per genotype at each time point. ${ }^{*} p<0.05$.

each time point in $\mathrm{MRF}^{\mathrm{FL} / \mathrm{FL}}$ and $\mathrm{MRF}^{\mathrm{WT} / \mathrm{FL}}$ mice, no colocalization between eYFP and NG2 was ever observed (Fig. 7J and data not shown). A similar lack of colocalization with eYFP and PDGFR $\alpha$ was seen (Fig. $7 K$ ), with only a single $\mathrm{eYFP}^{+/}$ PDGFR $\alpha^{+}$colabeled cell counted at the 8 week time point in the $\mathrm{MRF}^{\mathrm{FL} / \mathrm{FL}}$ mice (representing 1 of $802 \mathrm{eYFP}^{+}$cells assessed for PDGFR $\alpha$ expression for this condition, or $0.12 \%$ ). A single $\mathrm{eYFP}^{+} / \mathrm{PDGFR}^{+}$cell was also observed in a control $\left(\mathrm{MRF}^{\mathrm{WT} / \mathrm{FL}}\right)$ cortex at 2 weeks after $4 \mathrm{OHT}$, suggesting that these cells represented extremely rare incidences of recombination in OPCs rather than reexpression of OPC markers in the cells after ablation of MRF.

\section{Increased oligodendrocyte death and generation after} ablation of MRF

The decrease in density of $\mathrm{eYFP}^{+}$recombined oligodendrocytes in the $\mathrm{MRF}^{\mathrm{FL} / \mathrm{FL}} \mathrm{iCKO}$ mice relative to the $\mathrm{MRF}^{\mathrm{WT} / \mathrm{FL}}$ controls at later time points suggested that many of the recombined oligodendrocytes may undergo some form of cell death after loss of MRF. To confirm this, we stained spinal cord sections from the $\mathrm{MRF}^{\mathrm{WT} / \mathrm{FL}}$ or $\mathrm{MRF}^{\mathrm{FL} / \mathrm{FL}}$; PLP-CreERT ${ }^{+}$and Rosa26-eYFP ${ }^{+}$ mice with antibodies against active caspase- 3 as a marker for apoptosis. Control mice showed a very low incidence of apoptotic cells at all time points (approximately one active caspase $-3^{+}$cell per every 5-10 sections); none of the apoptotic cells detected in control mice were eYFP ${ }^{+}$. At both 2 and 4 weeks after $4 \mathrm{OHT}$, the iCKO mice showed a significant increase in the incidence of active caspase- $3^{+}$cells (approximately one per section, $p<0.05$ ), with a trend toward increased apoptosis also seen at 6 and 8 weeks after 4OHT (Fig. $8 A$ ). These apoptotic cells were a mix of $\mathrm{eYFP}^{+}$cells and eYFPnegative $\left(\mathrm{eYFP}^{-}\right.$) cells (Fig. $\left.8 A, B\right)$. The $\mathrm{eYFP}^{-}$, active caspase $-3^{+}$cells presumably consisted of both oligodendrocytes that had undergone recombination at the MRF but not Rosa26-eYFP locus, as well as other cells undergoing apoptosis in response to the demyelination and inflammatory environment.

The maintenance of relatively normal numbers of $\mathrm{CC}^{+}{ }^{+}$oligodendrocytes despite substantial loss of the recombined $\mathrm{iCKO}$ cells (Figs. 6, 7) and the reexpression of the non-recombined MRF and myelin genes in the iCKO mice at 6-8 weeks after $4 \mathrm{OHT}$ (Fig. 4) strongly suggested replacement of recombined cells by newly generated oligodendrocytes. To confirm this, we treated an additional cohort of $\mathrm{MRF}^{\mathrm{FL} / \mathrm{FL}}$ controls and $\mathrm{MRF}^{\mathrm{FL} / \mathrm{FL}}$; PLP-CreERT iCKOs with the thymidine analog EdU from 1 week after $4 \mathrm{OHT}$ and assessed the proportion of $\mathrm{CC}^{+}{ }^{+}$oligodendrocytes in the optic nerve that had incorporated EdU at 2-8 weeks after 4OHT. Control mice showed relatively limited incorporation of EdU over the experimental time course, and by 8 weeks after $4 \mathrm{OHT}$, only $2.6 \pm 1.0 \%$ of $\mathrm{CC}^{+}{ }^{+}$cells were $\mathrm{EdU}^{+}$(Fig. $8 C-E)$, consistent with previous reports of sporadic differentiation of new oligodendrocytes in the adult CNS (Rivers et al., 2008). In contrast, the $\mathrm{iCKO}$ mice showed a strong increase in the density of EdU ${ }^{+}$cells in the optic nerve relative to controls from 6 weeks after $4 \mathrm{OHT}$, and many of these $\mathrm{EdU}^{+}$cells were $\mathrm{CC}^{+}$. By 8 weeks after $4 \mathrm{OHT}, 35.6 \pm 7.0 \%$ of $\mathrm{CC}^{+}{ }^{+}$oligodendrocytes in the $\mathrm{iCKO}$ nerves were $\mathrm{EdU}^{+}$, indicating that they were newly generated from dividing OPCs in response to the demyelination (Fig. 8D,E).

Surviving recombined cells do not reenter the cell cycle but display deficits in myelin maintenance

To further investigate whether the oligodendrocytes in which MRF had been ablated were capable of "de-differentiating" and reentering the cell cycle, an additional cohort of $\mathrm{MRF}^{\mathrm{WT} / \mathrm{FL}}$ or $\mathrm{MRF}^{\mathrm{FL} / \mathrm{FL}}$; PLP-CreERT; Rosa26-eYFP mice were administered with EdU from 1 to 8 weeks after $4 \mathrm{OHT}$ (Fig. 8 F). At 8 weeks after $4 \mathrm{OHT}$, none of the $\mathrm{eYFP}^{+}$cells in the $\mathrm{MRF}^{\mathrm{WT} / \mathrm{FL}}$ control optic nerves were $\mathrm{EdU}^{+}$, and only an extreme minority $(0.42 \pm 0.22 \%)$ of the $\mathrm{eYFP}^{+}$cells in the $\mathrm{MRF}^{\mathrm{FL} / \mathrm{FL}} \mathrm{iCKO}$ optic nerves were $\mathrm{EdU}^{+}$ ( $p>0.05$ for difference between genotypes, 2580 and 1937 $\mathrm{eYFP}^{+}$cells analyzed for EdU incorporation in controls and iCKOs, respectively). This is consistent with the general lack of reexpression of OPC markers NG2 and PDGFR $\alpha$ in iCKO cells (Fig. 7), suggesting that the recombined oligodendrocytes do not reenter the cell cycle after the ablation of MRF.

Although the optic nerve and spinal cords contained a significant number of surviving recombined iCKO cells at 8 weeks after recombination (Figs. 7, 8), the high density of oligodendrocytes in these white matter tracts made assessment of the morphology of individual cells difficult. We therefore stained the cerebral cortex of $\mathrm{MRF}^{\mathrm{WT} / \mathrm{FL}}$ or $\mathrm{MRF}^{\mathrm{FL} / \mathrm{FL}}$; PLP-CreERT ${ }^{+}$and Rosa26$\mathrm{eYFP}^{+}$mice at 8 weeks after $4 \mathrm{OHT}$, colabeling with antibodies 

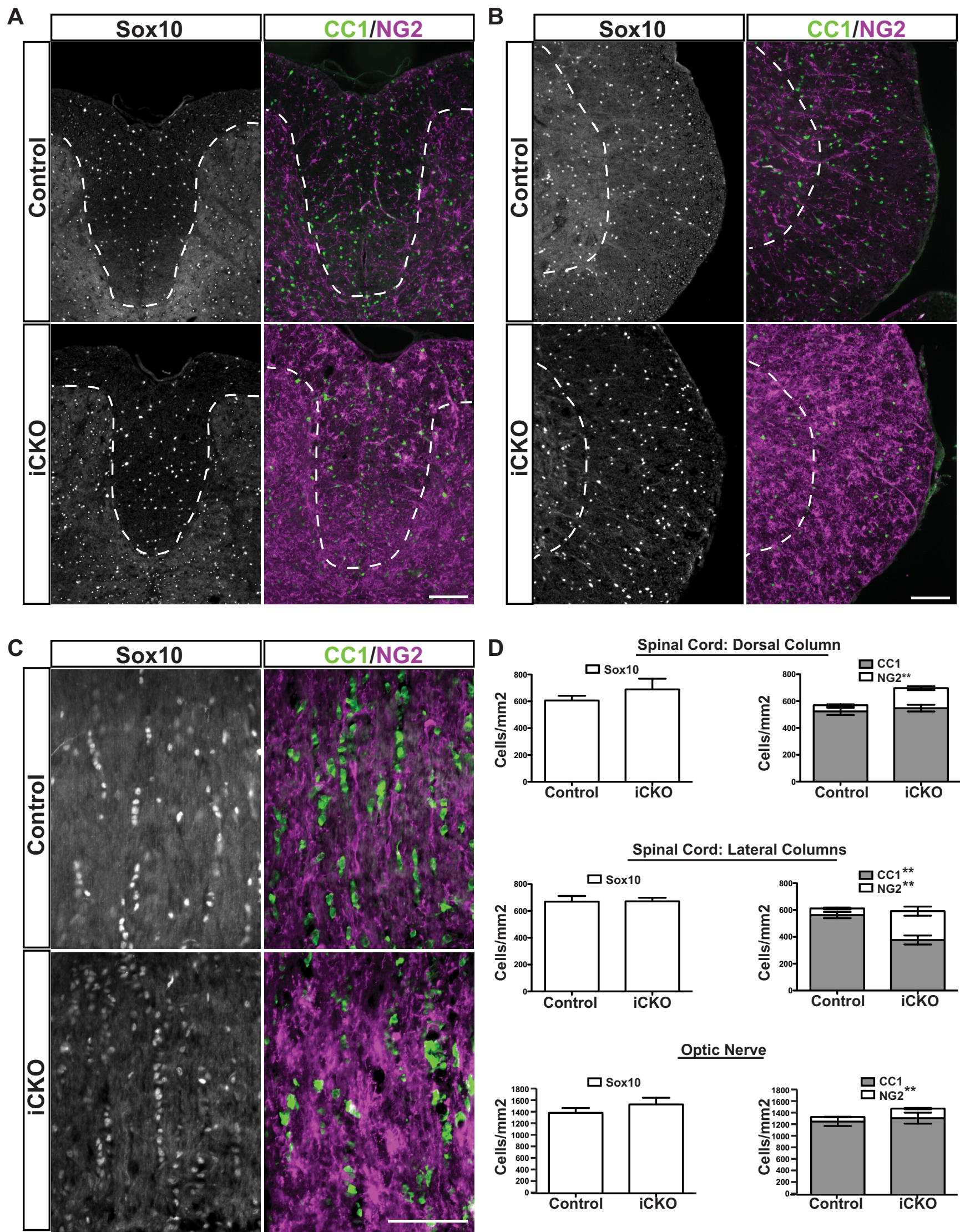

Figure 6. Immunohistochemical analysis of the oligodendrocyte lineage at peak clinical severity. $\boldsymbol{A}-\boldsymbol{C}$, Sox10, $C(\mathrm{C} 1$, and NG2 staining in the dorsal column of the spinal cord (A), the lateral white matter of the spinal cord (B), and optic nerve (C).D, Quantification of the densities of Sox10, NG2, and CC1 immunopositive cells in control and iCKO mice for each region. The density of Sox $10^{+}$cells was not significantly different between genotypes in any region analyzed, although NG2 ${ }^{+}$numbers were significantly elevated in the iCKO mice in each region. The density of $\mathrm{CC}^{+}{ }^{+}$cells was reduced in the iCKO animals relative to controls only in the lateral white matter of the spinal cord. ${ }^{* *} p<0.01 . n=5$ mice per genotype. Scale bars, $100 \mu \mathrm{m}$. 


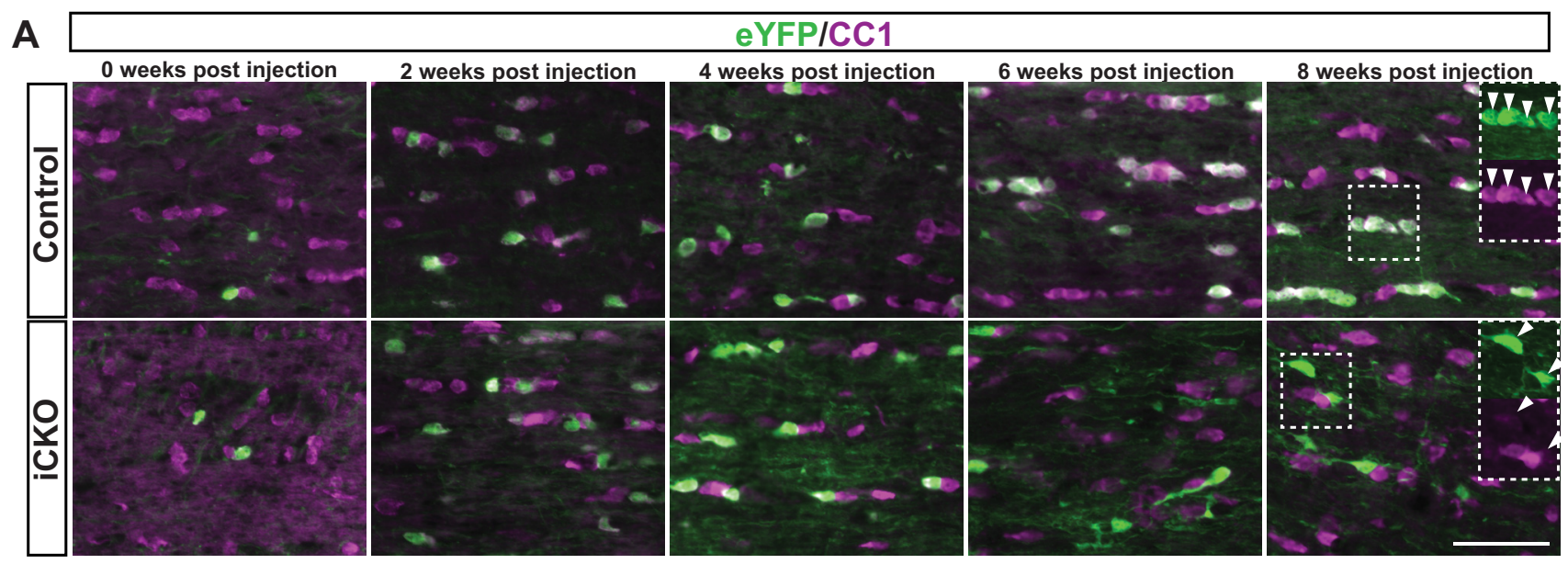

B Density Cc1+ oligodendrocytes C

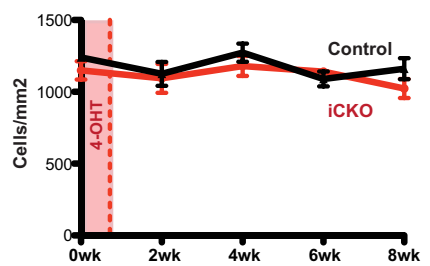

$\%$ oligodendrocytes eYFP+

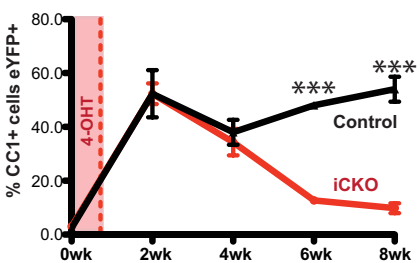

D

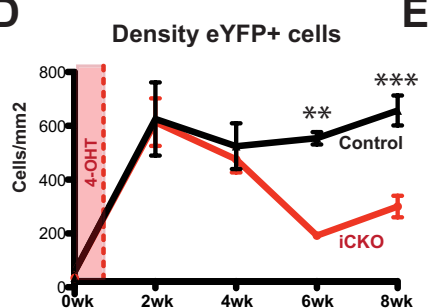

E

$\%$ eYFP+ cells +ve for CC1+

F

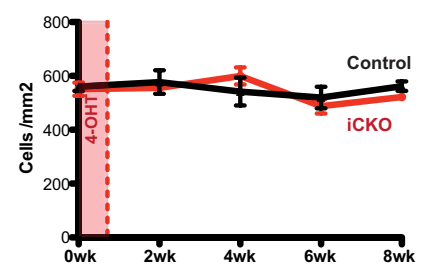

$\%$ oligodendrocytes eYFP+ $\mathbf{H}$

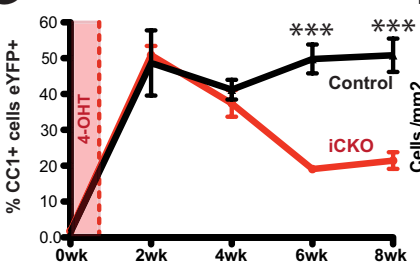

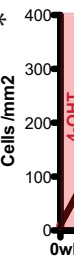

Density eYFP+ cells

$$
\text { I }
$$

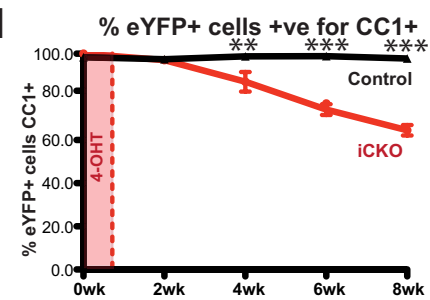

\section{$\mathbf{J}$}

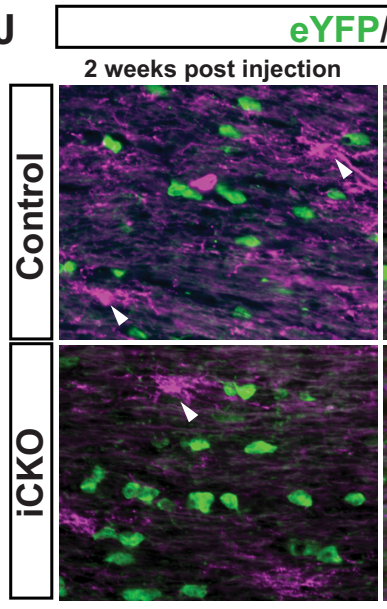

$\mathrm{K}$ 8 weeks post injection

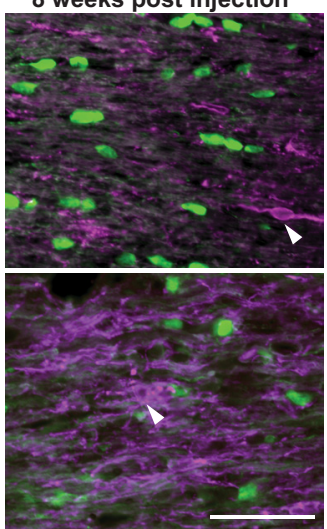

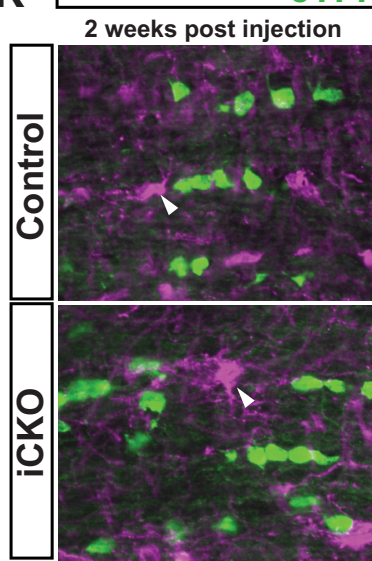

eYFP/PDGFRa

8 weeks post injection

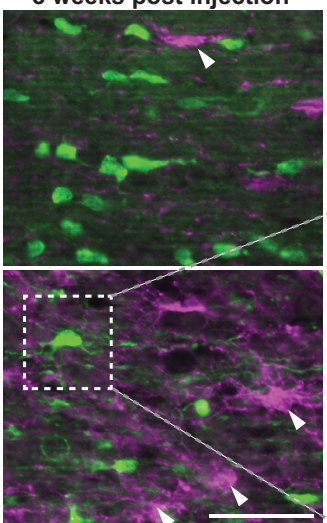

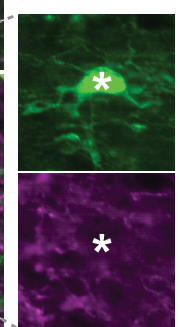

Figure 7. Ablation of MRF causes a delayed loss of mature phenotype and loss of many of the recombined oligodendrocytes. $A$, Representative optic nerve sections from MRF WT/FL/PLP-CreERT/ Rosa26 - eYFP (control) and from MRF FL/FL/PLP-CreERT/Rosa26 - eYFP (iCKO) mice either untreated with 40HT (0 week) or 2, 4, 6, or 8 weeks after 40HT stained with CC 1 and anti-eYFP. Insets in the "8 weeks post injection" images show separated channels for the boxed regions. $\boldsymbol{B}-\mathbf{I}$, Quantification of the density of $\mathrm{CC}^{+}{ }^{+}$oligodendrocytes, the proportion of $\mathrm{CC} 1^{+}$oligodendrocytes expressing eYFP, the density of eYFP ${ }^{+}$cells, and the proportion of eYFP ${ }^{+}$cells expressing $C(1$ for control and iCKO animals at $0-8$ weeks after $40 \mathrm{HT}$ in the optic nerve $(\boldsymbol{B}-\boldsymbol{E})$ and spinal cord $(\boldsymbol{F}-\boldsymbol{I})$. ${ }^{*} p<0.05,{ }^{* *} p<0.01,{ }^{* * *} p<0.001 . n=3-5$ mice per condition. $\boldsymbol{J}, \boldsymbol{K}$, Optic nerve sections stained with anti-eYFP and the OPC marker NG2 $(\boldsymbol{J})$ and PDGFR $\alpha(\boldsymbol{K})$ showing an absence of colocalization. NG2 ${ }^{+}$and PDGFR $\alpha{ }^{+}$cell bodies indicated by arrowheads. Scale bars, $50 \mu \mathrm{m}$.

against eYFP and oligodendrocyte lineage markers. Control $\left(\mathrm{MRF}^{\mathrm{WT} / \mathrm{FL}}\right) \mathrm{eYFP}^{+}$cells invariably stained with CNP, with eYFP also present in $\mathrm{CNP}^{+}$myelin internodes (Fig. 9A). In contrast, the $\mathrm{iCKO} \mathrm{eYFP}^{+}$cells showed varying levels of CNP expression, often being negative or only faintly positive, and typically had a series of fine processes not obviously associated with myelin internodes. Intact appearing myelin in these sections was almost invariably eYFP ${ }^{-}$(i.e., associated with non-recombined or newly generated oligodendrocytes). Similar observations were made in the striatum (Fig. 9B), in which the iCKO eYFP ${ }^{+}$oligodendro- 
A

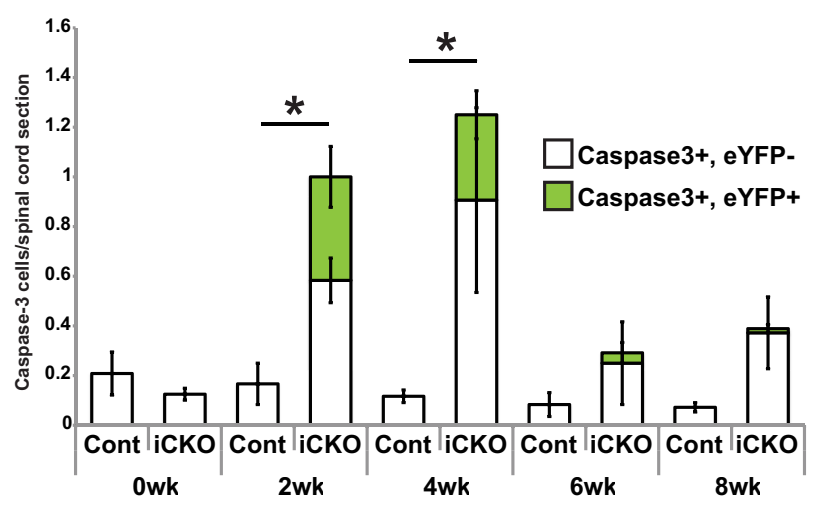

B

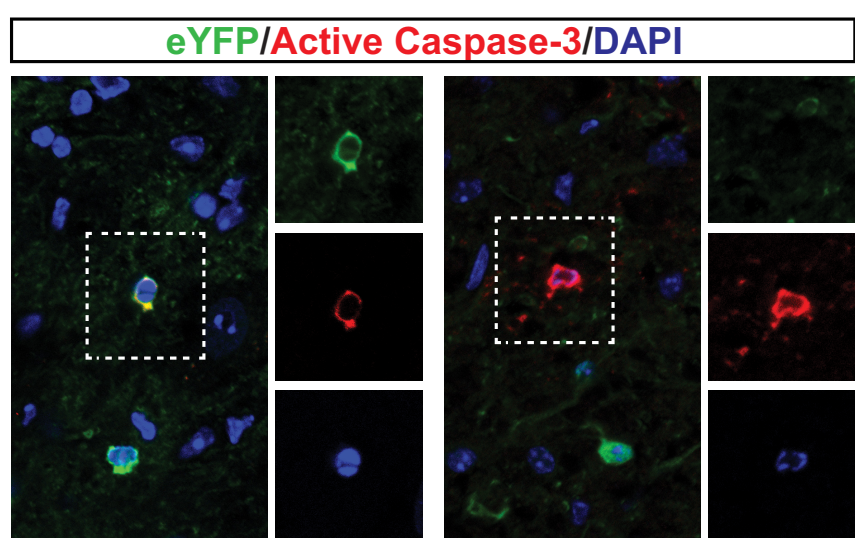

C

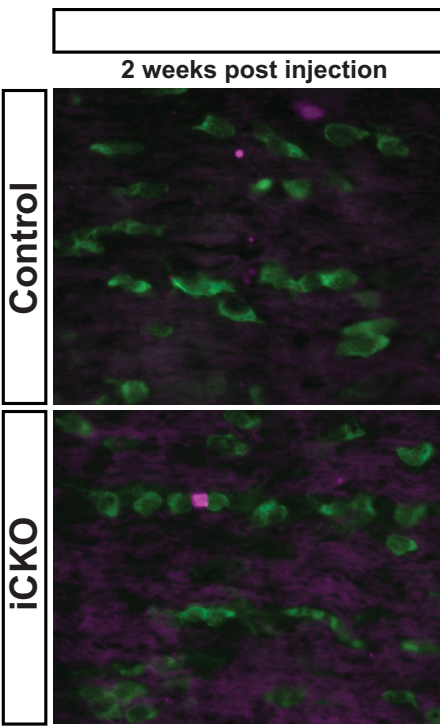

4 weeks post injection

CC1/EdU

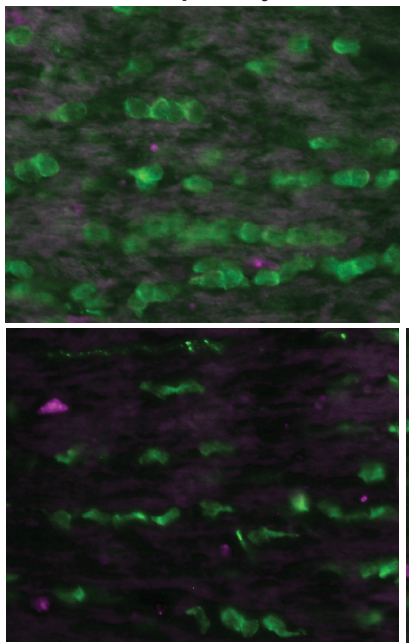

6 weeks post injection

8 weeks post injection

D

Density of newly generated oligodendrocytes

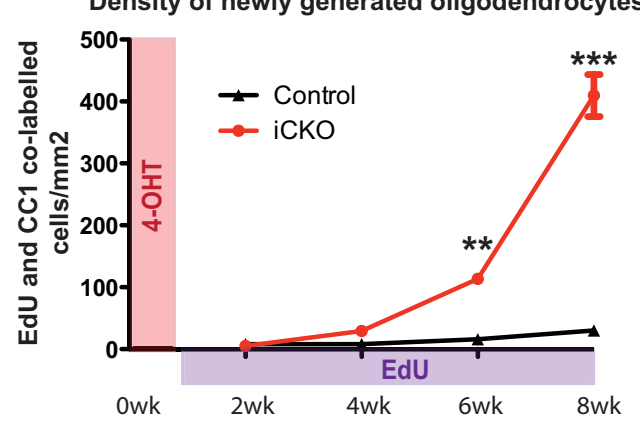

$\mathbf{F}$
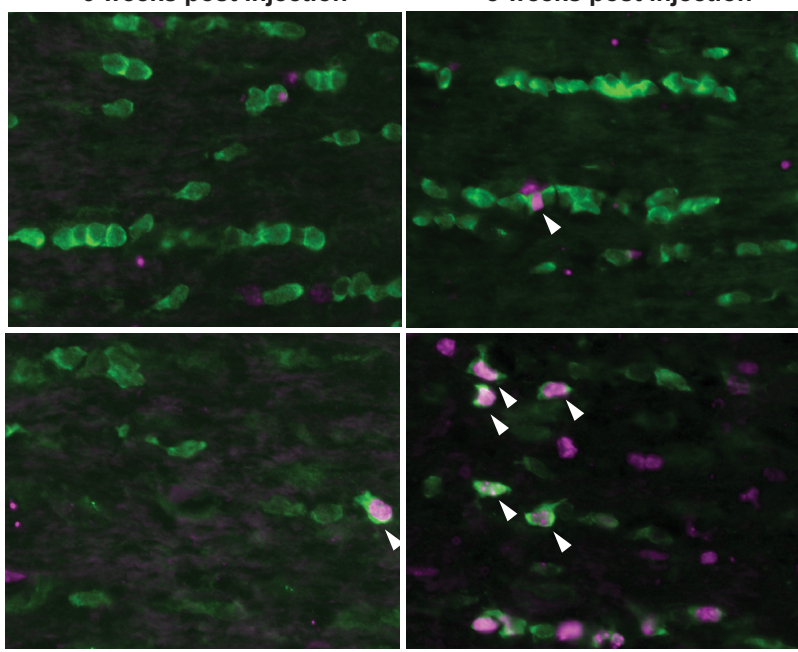

E
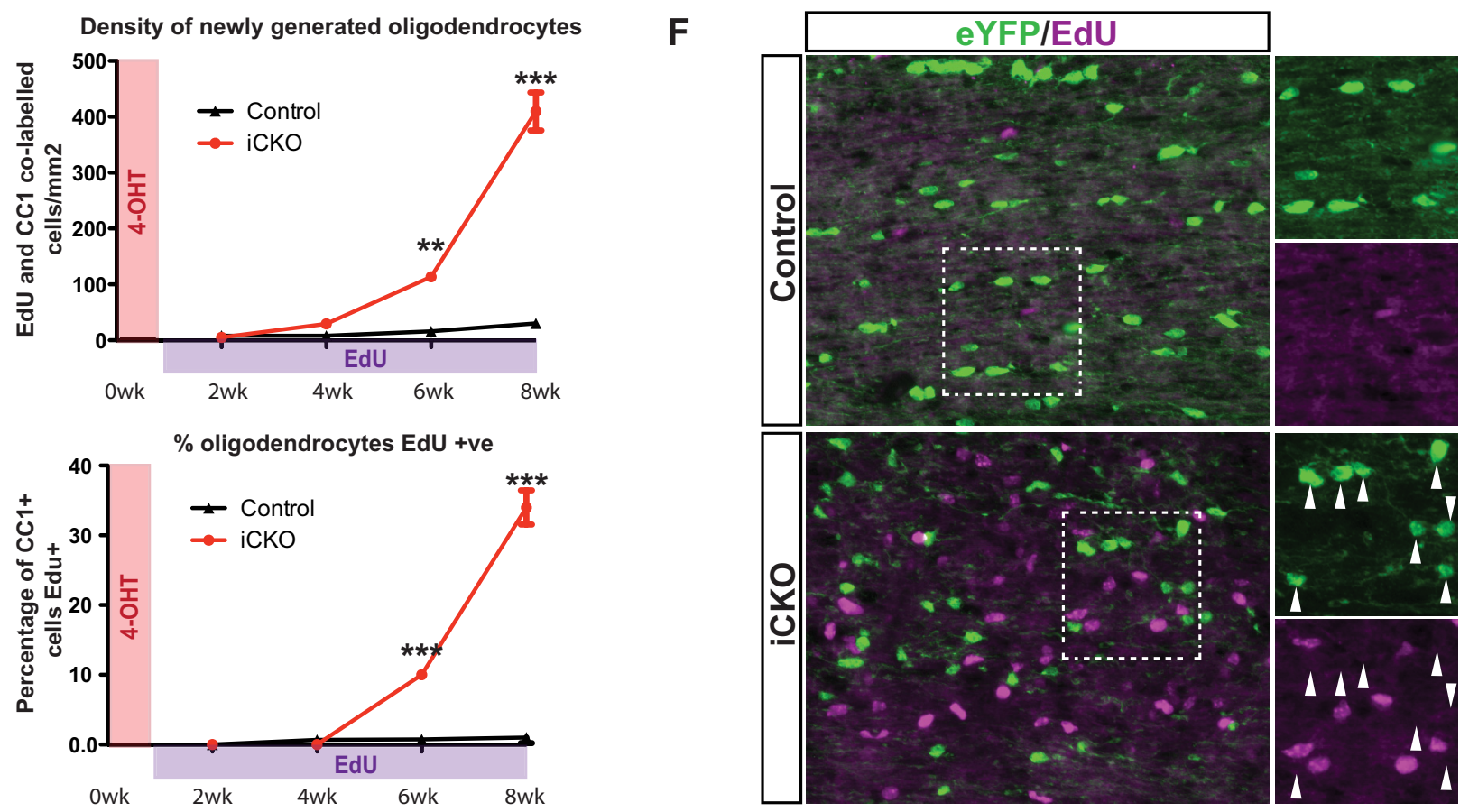

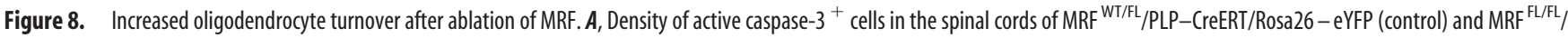
PLP-CreERT/Rosa26 - eYFP (iCKO) mice after 40HT administration. These apoptotic cells included both eYFP ${ }^{+}$recombined oligodendrocytes and eYFP ${ }^{-}$cells $(\boldsymbol{B})$; both (Figure legend continues.) 
cytes were a mix of $\mathrm{CNP}^{+}$cells still associated with myelin and cells that had apparently lost their myelin. As in the optic nerve and spinal cord, the iCKO eYFP ${ }^{+}$cells in the cortex were typically only faintly positive or negative for CC1 but still did not stain for OPC or astrocyte markers, such as NG2 (Fig. 9D) and GFAP (Fig. $9 E)$. These data indicate that, after the ablation of MRF, the recombined oligodendrocytes either undergo apoptosis or, if they survive, essentially lose the expression of mature markers and their associated myelin.

\section{Demyelination caused by MRF ablation is associated with innate immune system activation and axonal damage}

To characterize the secondary responses to the demyelination resulting from MRF ablation, we stained sections from spinal cord, brain, and optic nerve of control $\mathrm{MRF}^{\mathrm{FL} / \mathrm{FL}}$ and $\mathrm{iCKO}$ $\mathrm{MRF}^{\mathrm{FL} / \mathrm{FL}}$; PLP-CreERT mice with antibodies against microglia, lymphocytes, astrocytes, and axonal damage. Staining for CD68 revealed that the demyelination caused by ablation of MRF was associated with severe infiltration of activated microglia/macrophages into the white matter, many of which could be seen to colocalize with MBP, indicating active engulfment of myelin debris (Fig. 10A,B). To assess whether the demyelination and microglial activation were associated with lymphocyte infiltration, we stained spinal cord sections with anti-CD3 (for T cells) and B220 (for B cells), using sections from MOG 35-55-induced EAE sections as a positive control. Whereas the EAE spinal cord sections showed clear evidence of infiltration of $\mathrm{CD}^{+} \mathrm{T}$ cells in regions of demyelination, no such infiltration was evident in the demyelinated tissue of the iCKO mice (Fig. 10C). Quantification of the density of $\mathrm{CD}^{+}$cells in the iCKO and control mice confirmed extremely low numbers of $\mathrm{CD}^{+}$cells in each genotype (1.09 \pm 0.69 and $1.25 \pm 0.79$ cells $/ \mathrm{mm}^{2}$ in the dorsal columns and $0.28 \pm 0.28$ and $0.99 \pm 0.99$ cells $/ \mathrm{mm}^{2}$ in the dorsal columns for iCKO and control mice, respectively, $p>0.05)$. Similarly, no detectable increase in staining was seen with the B-cell marker anti-CD45R/B220 (data not shown). To assess whether the demyelination and innate immune system activation was associated with astroglial activation or axonal damage, we stained sections of control and iCKO mice at 8 weeks after $4 \mathrm{OHT}$ for GFAP and $\beta$-APP. The iCKO mice showed a clear increase in GFAP staining throughout the CNS (shown for the spinal cord in Fig. 10D), particularly evident in the white matter. Both control and iCKO mice displayed weak cytoplasmic staining for $\beta$-APP in both neurons and glia; however, iCKO mice displayed additional intense staining in axon bulbs throughout all white matter regions analyzed (lateral and dorsal white matter of the spinal cord, the corpus callosum, and optic nerve) (Fig. 10E-G).

\section{Discussion}

MRF is required for maintenance of oligodendrocyte viability and myelin gene expression in the adult CNS

We have previously reported a vital role for MRF in oligodendrocyte differentiation and CNS myelination during postnatal devel-

$\leftarrow$

(Figure legend continued.) examples are from iCK0 nerve at 4 weeks after $40 \mathrm{HT} . n=5$ mice per condition. C, Images showing EdU incorporation and $\mathrm{CC} 1$ immunohistochemistry at weeks 2-8 after $40 \mathrm{HT}$ in the optic nerves of control (MRF ${ }^{\mathrm{FL} / \mathrm{FL}}$ ) or iCKO (MRF ${ }^{\mathrm{FL} / \mathrm{FL}}$; PLP-CreERT) mice. $\boldsymbol{D}, \boldsymbol{E}$, Analysis of the density of $\mathrm{CC}^{+} / \mathrm{EdU}^{+}$double-labeled cells $(\boldsymbol{D})$ and the proportion of $\mathrm{CC}^{+}{ }^{+}$oligodendrocytes EdU ${ }^{+}(\boldsymbol{E})$ at weeks $2-8$ after $40 \mathrm{HT}$ in the optic nerves from $\mathrm{C} . n=3-5$ mice per condition. $\boldsymbol{F}$, Double staining for eYFP and EdU incorporation in representative MRF WT/FL/PLPCreERT/Rosa26 - eYFP (control) and MRF FL/FL/PLP-CreERT/Rosa26-eYFP (iCKO) optic nerve sections at 8 weeks after $40 \mathrm{HT}$. The eYFP ${ }^{+}$recombined oligodendrocytes (arrowheads) in both genotypes are overwhelmingly $(>99 \%) \mathrm{EdU}^{-} .{ }^{*} p<0.05,{ }^{* *} p<0.01,{ }^{* * *} p<0.001$. opment (Emery et al., 2009). This previous study did not address whether MRF was only transiently required for the transition from a premyelinating to a myelinating oligodendrocyte or whether it was required on an ongoing basis in the mature cells. Here, we provide evidence that conditional ablation of MRF within myelinating oligodendrocytes in the adult CNS causes delayed but severe demyelination. This demyelination is preceded by a rapid downregulation of many myelin genes, coincides with a loss of mature markers within the recombined oligodendrocytes, and is associated with the death and replacement of many of the recombined oligodendrocytes. These results demonstrate that MRF is not only required during oligodendrocyte differentiation but is also required on an ongoing basis for the maintenance of expression of myelin genes and for the maintenance of a mature, viable oligodendrocyte phenotype.

Previous iCKO strategies have identified roles for Egr2/ Krox-20 and Sox10 in maintenance of myelin within the adult PNS (Decker et al., 2006; Bremer et al., 2011). In those two studies, the kinetics of demyelination observed were vastly different, occurring within a matter of days after Egr2 ablation but taking weeks after Sox10 inactivation. The slow kinetics of demyelination seen after ablation of MRF or Sox10, versus the fast kinetics seen after ablation of Egr2, strongly suggest that different mechanisms are at play. It seems likely that the PNS demyelination seen after Egr2 inactivation is attributable to an active process of Schwann cell de-differentiation (as suggested by Decker et al., 2006), whereas the demyelination seen after ablation of Sox 10 or MRF is a more gradual one, with loss of the oligodendrocytes and myelin sheaths secondary to transcriptional dysregulation.

The eYFP labeling experiments demonstrated that, after ablation of MRF, many of the oligodendrocytes downregulate the expression of the mature marker APC/CC1 without reexpressing OPC markers such as NG2 or PDGFR $\alpha$. In the vast majority of cases ( $>99 \%)$, these cells also failed to incorporate EdU, despite robust proliferation around them, indicating that they do not reenter the cell cycle. This demonstrates that, in the absence of continued MRF expression, oligodendrocytes lose their "mature" phenotype without fully reverting to a progenitor/OPC stage. These findings seem similar to analogous experiments within sensory neurons in which inducible ablation of Islet 1 after their specification results in a loss of mature markers without causing reexpression of early genes (Sun et al., 2008). Although dedifferentiation of mature oligodendrocytes and reentry into the cell cycle has been reported in other contexts, such as in response to bFGF in vitro (Grinspan et al., 1996), our results suggest that it may not occur readily in vivo, given that we failed to see evidence of it even in the context of severe demyelination and with the ablation of a pro-differentiation transcription factor.

Apoptosis of recombined oligodendrocytes was observed at 2 and 4 weeks after $4 \mathrm{OHT}$, and a substantial decrease (of 50\%) in numbers of recombined oligodendrocytes was detectable in the iCKOs by $6-8$ weeks after $4 \mathrm{OHT}$. Given that in other mouse models oligodendrocyte death typically precedes overt demyelination by several weeks (Hesse et al., 2010; Traka et al., 2010; Pohl et al., 2011), some of the demyelination seen at 8 weeks after $4 \mathrm{OHT}$ is almost certainly a result of this apoptosis. A number of observations point to the likelihood that the recombined iCKO oligodendrocytes surviving at 8 weeks after $4 \mathrm{OHT}$ had also lost the ability to maintain myelin, however. These include the rapid downregulation of myelin genes PLP and MAG at 1 week after 4OHT (before any detectable loss of recombined cells and when the recombined MRF allele was still being expressed at control levels), the gradual loss of markers usually associated with myeli- 

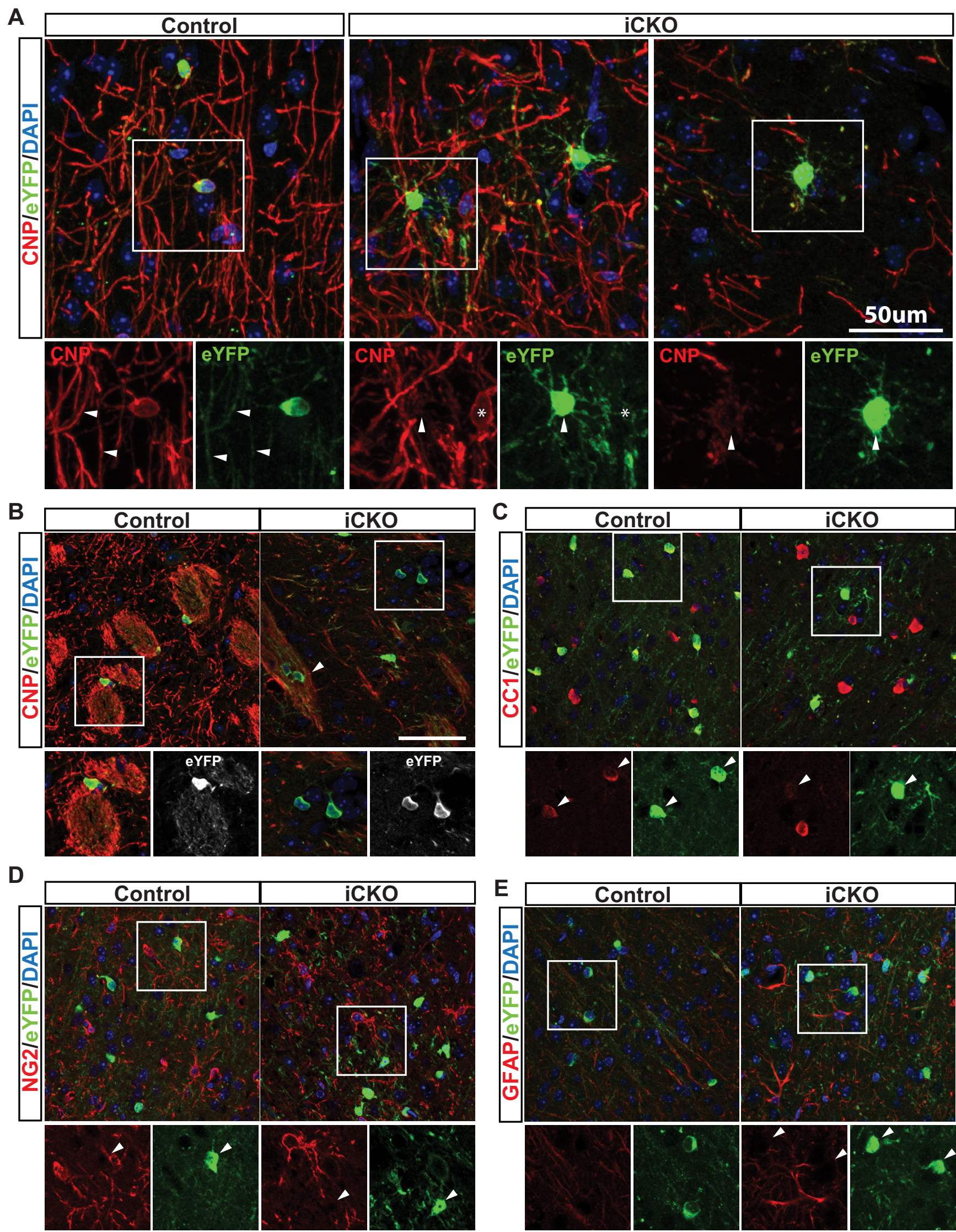

Figure 9. Surviving eYFP ${ }^{+}$iCKO cells losetheirmaturephenotype.A,Staining foreYFPand CNP inthecerebral cortex of control andiCKO miceat8 8 weeks after $40 \mathrm{HT}$.ControleYFP ${ }^{+}$cells arestronglyCNP ${ }^{+}$and associated with myelin internodes. iCKO eYFP ${ }^{+}$cells (arrowheads) areCNP ${ }^{-}$or only weakly positive and display multiplefineprocesses notassociated with myelin intermodes. Myelinating oligodendrocytes presentin theiCKO cortexare generally eYFP $\left.{ }^{-}{ }^{*}\right) \cdot B$, A similar loss of CNP expression and association with myelin internodes can be observed in the striatum of iCKO mice, though some eYFP + cells remain associated with myelin (arrowhead). As in the optic nerve, iCKO eYFP ${ }^{+}$cells within the cortex downregulate the expression of $C(1$ antigen $(\boldsymbol{C})$ but remain negative for NG2 (D) and GFAP(E). 
A

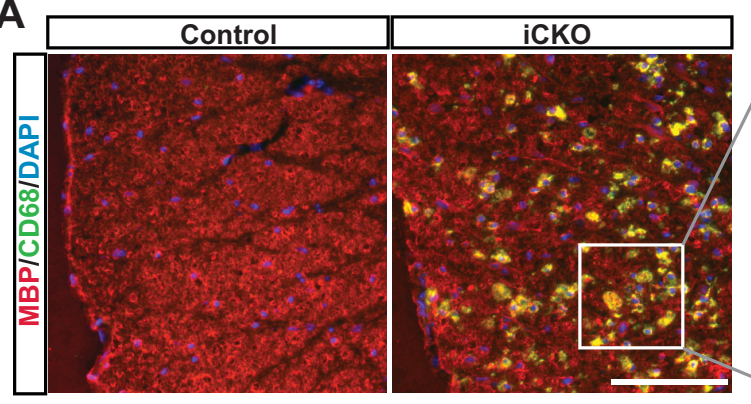

C

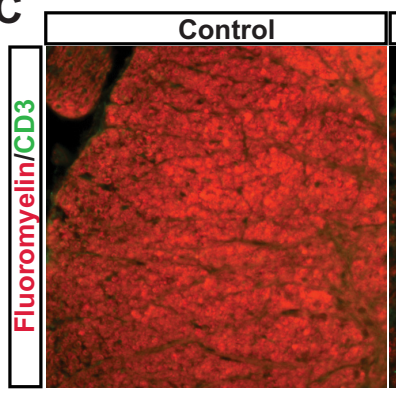

E

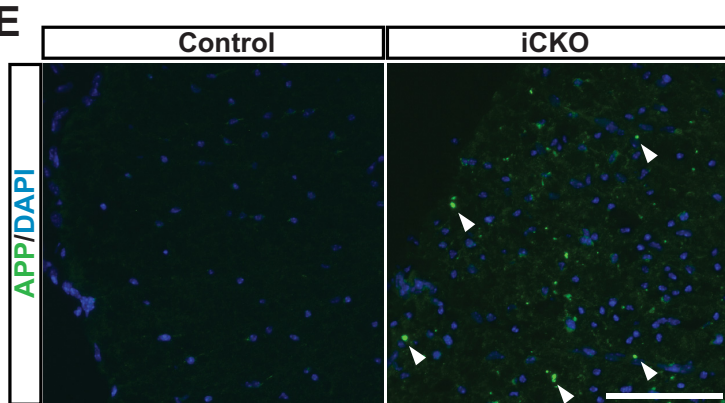

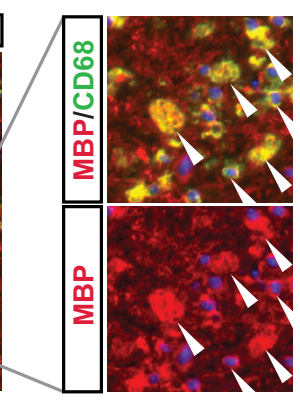

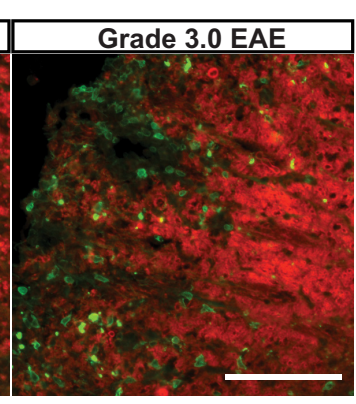

$F$

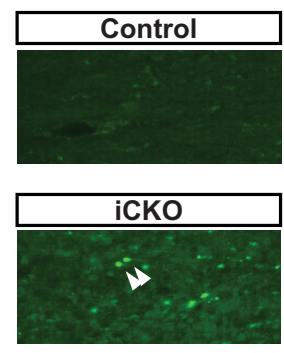

B
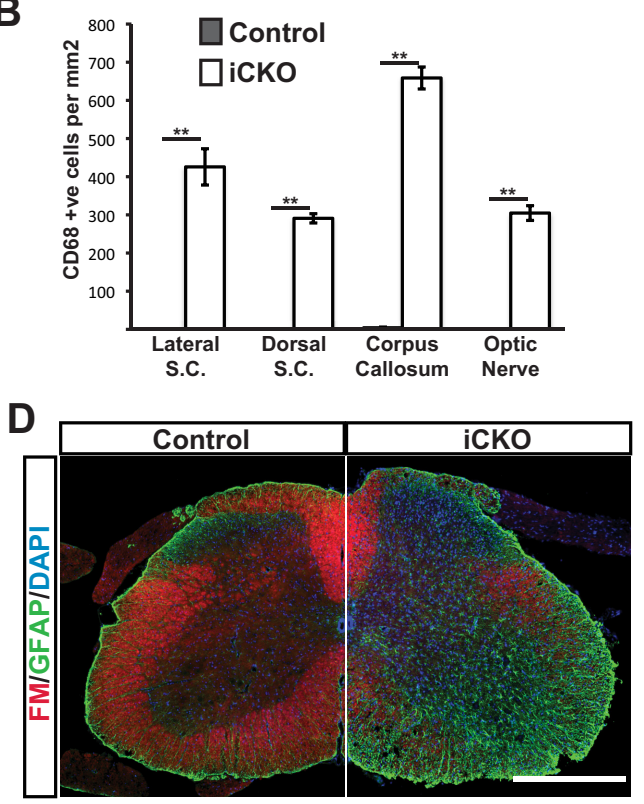

G

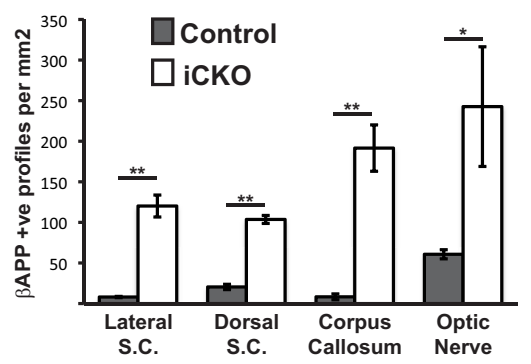

Figure 10. Demyelination caused by ablation of MRF is associated with activated microglia/macrophages and axonal damage. $A$, Representative sections stained for MBP and CD68 in the lateral columns of the spinal cord (S.C.) in a control and an iCK0 animal at 8 weeks after $40 \mathrm{HT}$. Much of the MBP staining present colocalizes with the CD68 ${ }^{+}$microglia/macrophages (inset, arrowheads). $B$, Quantification of the density of $\mathrm{CD} 68{ }^{+}$microglia/macrophages in key white matter regions. $C$, Anti-CD3 staining in the lateral columns of a control and iCKO animal at 8 weeks after $40 \mathrm{HT}$ and the equivalent region of an EAE mouse. $\boldsymbol{D}$, Representative image of a control and iCKO spinal cord stained with anti-GFAP. $\boldsymbol{E}, \boldsymbol{F}$, Representative sections stained for $\beta$-APP in the lateral columns of the spinal cord $(\boldsymbol{E})$ and corpus callosum $(\boldsymbol{F})$ of a control and iCKO at 8 weeks after $40 \mathrm{HT}$. Arrowheads indicate $\beta$-APP ${ }^{+}$axonal terminal bulbs. $\mathbf{G}$, Quantification of the density of $\beta$-APP ${ }^{+}$axon terminal bulbs in key white matter regions. Graphs show means \pm SEMs, $n=5$ animals per genotype. ${ }^{*} p<0.05,{ }^{* *} p<0.01$. Scale bars, $100 \mu \mathrm{m}$

nating cells (such as $\mathrm{CC} 1$ and $\mathrm{CNP}$ ) and the observation that the processes of the surviving $\mathrm{eYFP}^{+} \mathrm{iCKO}$ cells at 8 weeks after $4 \mathrm{OHT}$ generally no longer appeared to be associated with intact myelin sheaths. Compacted myelin in vivo is thought to be a remarkably stable structure (for review, see Aggarwal et al., 2011); both the protein (Sabri et al., 1974) and lipid (Saher and Simons, 2010) components of myelin can have half-lives of months in vivo. Despite this stability, the components of myelin would appear to show some degree of turnover, and it seems likely that the dysregulation of myelin genes, such as PLP and MAG, ultimately leads to a loss of the ability of the cells to maintain their myelin sheaths independent of their survival.

\section{Remyelination after ablation of MRF}

After the clinical peak at 8 weeks, MRF iCKOs showed a gradual (and incomplete) clinical recovery that was associated with remyelination, as evidenced by an increase in the proportion of axons myelinated and an increase in $g$-ratios. Given the progressive incorporation of EdU into many of the $\mathrm{CC}^{+}{ }^{+}$oligodendrocytes in the iCKO mice at 6 and 8 weeks after recombination and the associated reexpression of the non-recombined MRF allele and myelin genes, this remyelination was almost certainly mediated by newly generated oligodendrocytes. Despite the presence of large numbers of newly generated oligodendrocytes observed in the EdU incorporation experiments at 8 weeks after $4 \mathrm{OHT}$, we saw substantial demyelination at this time point and only relatively limited evidence of remyelination in progress. This indicates that the processes of oligodendrocyte differentiation and successful remyelination can become uncoupled, eluding to the importance of identifying the relevant signals in the demyelinated environment that may block remyelination (Franklin and ffrench-Constant, 2008). The incomplete recovery of these mice even 8 months after clinical peak presumably reflects both the incomplete remyelination and irreversible axonal damage.

\section{MRF ablation as a new model for studying} demyelinating disease

There have recently been several mouse models reported that allow for the inducible ablation of oligodendrocytes (Buch et al., 2005; Traka et al., 2010; Pohl et al., 2011; Oluich et al., 2012). These models allow for the induction of a reproducible and widespread demyelination and analysis of the cellular events associated with it and the subsequent remyelination. One potential caveat with these genetic models is that many of them result in demyelination in both the CNS and PNS. Although the PLPCreERT transgenics used in this study targets recombination to 
both Schwann cells and oligodendrocytes (Doerflinger et al., 2003), MRF is not expressed in Schwann cells and does not have a role in peripheral myelination (LeDoux et al., 2006; Emery et al., 2009). Consistent with this, we did not observe any evidence of peripheral demyelination (e.g., clasping of hindlimbs when suspended from tail or by electron microscopy analysis at 8 weeks after 4OHT; data not shown). We observed significant innate, but not adaptive, immune system activation and axonal damage at clinical peak in our model, consistent with other inducible models of demyelination (Ghosh et al., 2011; Locatelli et al., 2012) and the axonal pathology associated with multiple sclerosis (Dutta and Trapp, 2007). Whether the axonal damage is a direct result of the demyelination or whether the axons were damaged in response to the microglial activation is difficult to determine without manipulation of the microglia, but this axonal damage may contribute to the ongoing clinical deficits seen in the 8 month recovery cohort. Feasibly, the mice presented in this study may prove an additional valuable genetic tool for studying the events associated with CNS demyelination and remyelination free of confounding PNS effects.

A downregulation of MRF has been observed in other demyelinating mouse models, including the mouse model of Niemann-Pick type C 1 (NPC1) disease (Yan et al., 2011) and the cuprizone model (Jurevics et al., 2002). Although it is not yet entirely clear whether the observed dysregulation of MRF in these models is a causal component of the demyelination or merely symptomatic of oligodendrocyte dysfunction and loss, our results support the notion that dysregulation of MRF in NPC1 or other diseases could feasibly have a key role in the ultimate loss of myelin. Although roles for MRF in human myelination have not yet been formally established, it is known that the human ortholog C11Orf9 is enriched in myelin-rich regions of the human brain (Oldham et al., 2008), downregulated in human fetuses with a lethal motor neuron/oligodendrocyte disease (Pakkasjarvi et al., 2005), and upregulated during differentiation of oligodendrocytes from human ES cells (Letzen et al., 2010), suggesting conserved roles in myelination between mice and humans. As such, identification of the mechanisms by which MRF expression is regulated and its roles in human diseases will be an important subject of future work.

\section{References}

Aggarwal S, Yurlova L, Simons M (2011) Central nervous system myelin: structure, synthesis and assembly. Trends Cell Biol 21:585-593.

Agrawal D, Hawk R, Avila RL, Inouye H, Kirschner DA (2009) Internodal myelination during development quantitated using X-ray diffraction. J Struct Biol 168:521-526.

Allen Institute for Brain Science (2009) Allen brain atlas. Seattle, WA: Allen Institute for Brain Science. Available at http://www.brain-map.org.

Bremer M, Fröb F, Kichko T, Reeh P, Tamm ER, Suter U, Wegner M (2011) Sox10 is required for Schwann-cell homeostasis and myelin maintenance in the adult peripheral nerve. Glia 59:1022-1032.

Buch T, Heppner FL, Tertilt C, Heinen TJ, Kremer M, Wunderlich FT, Jung S, Waisman A (2005) A Cre-inducible diphtheria toxin receptor mediates cell lineage ablation after toxin administration. Nat Methods 2:419-426.

Cahoy JD, Emery B, Kaushal A, Foo LC, Zamanian JL, Christopherson KS, Xing Y, Lubischer JL, Krieg PA, Krupenko SA, Thompson WJ, Barres BA (2008) A transcriptome database for astrocytes, neurons, and oligodendrocytes: a new resource for understanding brain development and function. J Neurosci 28:264-278.

Decker L, Desmarquet-Trin-Dinh C, Taillebourg E, Ghislain J, Vallat JM, Charnay P (2006) Peripheral myelin maintenance is a dynamic process requiring constant Krox20 expression. J Neurosci 26:9771-9779.

Doerflinger NH, Macklin WB, Popko B (2003) Inducible site-specific recombination in myelinating cells. Genesis 35:63-72.
Dutta R, Trapp BD (2007) Pathogenesis of axonal and neuronal damage in multiple sclerosis. Neurology 68:S22-S31; discussion S43-S54.

Emery B (2010) Regulation of oligodendrocyte differentiation and myelination. Science 330:779-782.

Emery B, Agalliu D, Cahoy JD, Watkins TA, Dugas JC, Mulinyawe SB, Ibrahim A, Ligon KL, Rowitch DH, Barres BA (2009) Myelin gene regulatory factor is a critical transcriptional regulator required for CNS myelination. Cell 138:172-185.

Faux C, Rakic S, Andrews W, Yanagawa Y, Obata K, Parnavelas JG (2010) Differential gene expression in migrating cortical interneurons during mouse forebrain development. J Comp Neurol 518:1232-1248.

Franklin RJ, ffrench-Constant C (2008) Remyelination in the CNS: from biology to therapy. Nat Rev Neurosci 9:839-855.

Ghosh A, Manrique-Hoyos N, Voigt A, Schulz JB, Kreutzfeldt M, Merkler D, Simons M (2011) Targeted ablation of oligodendrocytes triggers axonal damage. PLoS One 6:e22735.

Grinspan JB, Reeves MF, Coulaloglou MJ, Nathanson D, Pleasure D (1996) Re-entry into the cell cycle is required for bFGF-induced oligodendroglial dedifferentiation and survival. J Neurosci Res 46:456-464.

He Y, Dupree J, Wang J, Sandoval J, Li J, Liu H, Shi Y, Nave KA, CasacciaBonnefil P (2007) The transcription factor yin yang 1 is essential for oligodendrocyte progenitor differentiation. Neuron 55:217-230.

Hesse A, Wagner M, Held J, Brück W, Salinas-Riester G, Hao Z, Waisman A, Kuhlmann T (2010) In toxic demyelination oligodendroglial cell death occurs early and is FAS independent. Neurobiol Dis 37:362-369.

Jurevics H, Largent C, Hostettler J, Sammond DW, Matsushima GK, Kleindienst A, Toews AD, Morell P (2002) Alterations in metabolism and gene expression in brain regions during cuprizone-induced demyelination and remyelination. J Neurochem 82:126-136.

LeDoux MS, Xu L, Xiao J, Ferrell B, Menkes DL, Homayouni R (2006) Murine central and peripheral nervous system transcriptomes: comparative gene expression. Brain Res 1107:24-41.

Letzen BS, Liu C, Thakor NV, Gearhart JD, All AH, Kerr CL (2010) MicroRNA expression profiling of oligodendrocyte differentiation from human embryonic stem cells. PLoS One 5:e10480.

Ligon KL, Kesari S, Kitada M, Sun T, Arnett HA, Alberta JA, Anderson DJ, Stiles CD, Rowitch DH (2006) Development of NG2 neural progenitor cells requires Olig gene function. Proc Natl Acad Sci USA 103:7853-7858.

Locatelli G, Wörtge S, Buch T, Ingold B, Frommer F, Sobottka B, Krüger M, Karram K, Bühlmann C, Bechmann I, Heppner FL, Waisman A, Becher B (2012) Primary oligodendrocyte death does not elicit anti-CNS immunity. Nat Neurosci 15:543-550.

Lu QR, Sun T, Zhu Z, Ma N, Garcia M, Stiles CD, Rowitch DH (2002) Common developmental requirement for Olig function indicates a motor neuron/oligodendrocyte connection. Cell 109:75-86.

Oldham MC, Konopka G, Iwamoto K, Langfelder P, Kato T, Horvath S, Geschwind DH (2008) Functional organization of the transcriptome in human brain. Nat Neurosci 11:1271-1282.

Oluich LJ, Stratton JA, Lulu Xing Y, Ng SW, Cate HS, Sah P, Windels F, Kilpatrick TJ, Merson TD (2012) Targeted ablation of oligodendrocytes induces axonal pathology independent of overt demyelination. J Neurosci 32:8317-8330.

Pakkasjärvi N, Gentile M, Saharinen J, Honkanen J, Herva R, Peltonen L, Kestil ä M (2005) Indicative oligodendrocyte dysfunction in spinal cords of human fetuses suffering from a lethal motoneuron disease. J Neurobiol 65:269-281.

Pfaffl MW (2001) A new mathematical model for relative quantification in real-time RT-PCR. Nucleic Acids Res 29:e45.

Pohl HB, Porcheri C, Mueggler T, Bachmann LC, Martino G, Riethmacher D, Franklin RJ, Rudin M, Suter U (2011) Genetically induced adult oligodendrocyte cell death is associated with poor myelin clearance, reduced remyelination, and axonal damage. J Neurosci 31:1069-1080.

Qi Y, Cai J, Wu Y, Wu R, Lee J, Fu H, Rao M, Sussel L, Rubenstein J, Qiu M (2001) Control of oligodendrocyte differentiation by the Nkx2.2 homeodomain transcription factor. Development 128:2723-2733.

Rivers LE, Young KM, Rizzi M, Jamen F, Psachoulia K, Wade A, Kessaris N, Richardson WD (2008) PDGFRA/NG2 glia generate myelinating oligodendrocytes and piriform projection neurons in adult mice. Nat Neurosci 11:1392-1401. 
Sabri MI, Bone AH, Davison AN (1974) Turnover of myelin and other structural proteins in the developing rat brain. Biochem J 142:499-507.

Saher G, Simons M (2010) Cholesterol and myelin biogenesis. Subcell Biochem 51:489-508.

Srinivas S, Watanabe T, Lin CS, William CM, Tanabe Y, Jessell TM, Costantini F (2001) Cre reporter strains produced by targeted insertion of EYFP and ECFP into the ROSA26 locus. BMC Dev Biol 1:4.

Stolt CC, Rehberg S, Ader M, Lommes P, Riethmacher D, Schachner M, Bartsch U, Wegner M (2002) Terminal differentiation of myelinforming oligodendrocytes depends on the transcription factor Sox10. Genes Dev 16:165-170.

Sugimori M, Nagao M, Parras CM, Nakatani H, Lebel M, Guillemot F, Nakafuku M (2008) Ascll is required for oligodendrocyte development in the spinal cord. Development 135:1271-1281.

Sun Y, Dykes IM, Liang X, Eng SR, Evans SM, Turner EE (2008) A central role for Islet1 in sensory neuron development linking sensory and spinal gene regulatory programs. Nat Neurosci 11:1283-1293.

Takada N, Kucenas S, Appel B (2010) Sox10 is necessary for oligodendrocyte survival following axon wrapping. Glia 58:996-1006.

Traka M, Arasi K, Avila RL, Podojil JR, Christakos A, Miller SD, Soliven B, Popko B (2010) A genetic mouse model of adult-onset, pervasive central nervous system demyelination with robust remyelination. Brain 133:3017-3029.

Xin M, Yue T, Ma Z, Wu FF, Gow A, Lu QR (2005) Myelinogenesis and axonal recognition by oligodendrocytes in brain are uncoupled in Olig1null mice. J Neurosci 25:1354-1365.

Yan X, Lukas J, Witt M, Wree A, Hübner R, Frech M, Köhling R, Rolfs A, Luo J (2011) Decreased expression of myelin gene regulatory factor in Niemann-Pick type C 1 mouse. Metab Brain Dis 26:299-306.

Zhou Q, Anderson DJ (2002) The bHLH transcription factors OLIG2 and OLIG1 couple neuronal and glial subtype specification. Cell 109:61-73. 